\title{
不同介质中氰根传感器的研究进展
}

\author{
曲文娟*, 房 虎 ${ }^{a}$ 黄 青 ${ }^{a}$ 张有明 $*, a, b$ \\ 林 奇 $a$ 姚 虹 ${ }^{a}$ 魏太保*, $a$ \\ $\left({ }^{a}\right.$ 西北师范大学化学化工学院 生态环境相关高分子材料教育部重点实验室 \\ 甘肃省高分子材料重点实验室 兰州 730070) \\ ( $b$ 兰州城市学院 兰州 730070)
}

\begin{abstract}
摘要 氰根离子对于哺乳动物来说具有很强的毒性, 因为它会影响人体许多正常的功能，比如血管、视觉、中枢神经、 心脏、内分泌和代谢系统. 此外, 含㲵的盐类化合物仍然在人类的生产生活中广泛使用, 特别是在电镀和塑料制造业、 黄金和白银开采、制革工业、治金等方面，从而导致了环境的污染. 因此，人工合成的氰根选择性受体或苂光传感器在 阴离子识别领域引起了广泛的关注. 由于化学传感器具有合成方法简单、廉价、响应速度快, 以及与氰根反应前后比 色和/或荧光变化等优点, 因此在过去的数十年中, 被广大科研工作者深入研究. 根据在不同介质中的氰根离子响应, 本文从四个方面总结了 2010 年以来氰根离子传感器的研究进展: (1)纯有机相中的氰根离子识别, (2)含水介质中的氰 根离子识别, (3)纯水相中的氰根离子识别, (4)固相中的氰根离子识别. 这些传感器针对在溶液中和固体材料中氰根离 子的检测, 以及对㲵根离子裸眼检测的研究, 从而实现了在环境以及食物样品中方便、快捷地实时检测氰根离子.
\end{abstract}

关键词 氧根识别; 不同介质; 环境和食物样品; 应用工具

\section{Research Progress of Cyanide Sensors in Different Medium}

\author{
Qu, Wenjuan ${ }^{*, a}$ Fang, $\mathrm{Hu}^{a} \quad$ Huang, Qing ${ }^{a} \quad$ Zhang, Youming ${ }^{*, a, b}$ \\ Lin, $\mathrm{Qi}^{a} \quad$ Yao, Hong ${ }^{a} \quad$ Wei ,Taibao*,a \\ $\left({ }^{a}\right.$ Key Laboratory of Eco-Environment-Related Polymer Materials, Ministry of Education of China, Key Laboratory of \\ Polymer Materials of Gansu Province, College of Chemistry and Chemical Engineering, \\ Northwest Normal University, Lanzhou 730070) \\ ( ${ }^{b}$ Lanzhou City University, Lanzhou 730070)
}

\begin{abstract}
Cyanide ion has strong toxicity for mammals, because it can affect many normal function of body, such as blood vessels, visual, as well as central nervous system, heart, endocrine and metabolic system. In addition, the cyanide salts are widely used in the production of human life, especially in electroplating and plastic manufacturing, mining, gold and silver leather industry, metallurgy, etc., which resulting in the pollution of environment. Therefore, the artificial cyanide selective receptor or fluorescent sensor has attracted widely attention in the field of anionic recognition. Due to the advantages of simple synthesis method, low cost, fast response, colorimetry and/or fluorescence change before and after reaction with cyanide, chemical sensors have been deeply studied by many researchers in the past decades. Based on the reaction of cyanide ions in different media, the research progress of cyanide sensors is summarized since 2010 from four aspects: (1) identification of cyanide in pure organic phase, (2) identification of cyanide ions in aqueous media, (3) identification of cyanide ions in pure water phase, and (4) identification of cyanide ions in solid phase. These sensors for cyanide in solution and solid material test and detect cyanide by naked eyes, which realizes the convenient, fast and real-time detection of cyanide in environmental and food samples.

Keywords cyanide identification, different media, environmental and food samples, application tools
\end{abstract}

* Corresponding authors. E-mail: weitaibao@126.com; quwenjuanlz@163.com; zhangnwnu@126.com

Received October 16, 2018; revised December 27, 2018; published online January 31, 2019.

Project supported by the National Natural Science Foundation of China (Nos. 21661028, 21662031, 21574104).

国家自然科学基金(Nos. 21661028, 21662031, 21574104)资助项目. 
些受体在材料科学、环境科学和生物化学领域具有潜在 的应用价值 ${ }^{[1]}$. 由于阴离子的大小和形状的变化很大, 所以选择性阴离子受体的设计是一项极具挑战性的任 务, 但它仍然是超分子化学研究的一个重要领域 ${ }^{[2-7]}$. 从生理学上来说, 诸如 $\mathrm{Cl}^{-}, \mathrm{AcO}^{-}, \mathrm{CN}^{-}, \mathrm{F}^{-}, \mathrm{HSO}_{4}^{-}$这 些都广泛存在于生活和环境系统中, 并且以其在人体中 的各种重要角色而被熟知 ${ }^{[8 \sim 11]}$. 然而, 当它们的浓度超 过通常允许的限度时, 就会造成严重的有害影响 ${ }^{[2]}$. 而 在有害的阴离子中, 氧根离子最受关注. 氧根离子 $\left(\mathrm{CN}^{-}\right)$被认为是人体最致命的, 它可以影响人体的多种 功能, 包括视觉、血管、心脏、中枢神经、内分泌和代 谢系统 ${ }^{[13-19]}$. 氰化物可以通过皮肤、胃肠道和肺部吸收, 引起痉挛、呕吐、意识丧失, 最终死亡 ${ }^{[20,21]}$. 它能够破 坏线粒体中存在的电子传递系统, 导致猝死 ${ }^{[22,23]}$. 它的 毒性来自于它在细胞色素 $\mathrm{c}$ 氧化酶中与铁结合的能力, 干扰电子运输, 导致缺氧 ${ }^{[24 ~ 28] . ~}$

尽管有一些不利的影响, 但从积极的方面来看, 萻 离子仍然是一种非常重要的化学试剂, 在许多化学过程 中都是工业应用的，如黄金开采、电镀、首饰制作、 $\mathrm{X}$ 射线胶片复原、制革和冶金 ${ }^{[29 ~ 31]}$. 然而, 水溶性的氰化 物盐是最致命的污染和中毒的药物 ${ }^{[32,33]}$. 世界健康组织 (WHO) 允许饮用水中氧化物的最大污染量不超过 1.9 $\mu \mathrm{mol} \cdot \mathrm{L}^{-1}[34]$. 到目前为止, 大多数化学计量仪检测氰根

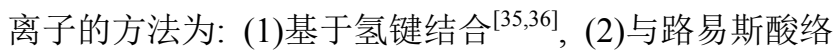
合 ${ }^{[37]},(3)$ 时间门苂光 ${ }^{[38]},(4)$ 量子点 ${ }^{[39]},(5)$ 金纳米粒子 ${ }^{[40]}$, (6)基于 $\mathrm{Al}_{2} \mathrm{O}_{3}$ 薄膜模型的化学传感 ${ }^{[41]}$, (7)与金属结合的 染料结构单元 ${ }^{[42]}$, (8) 共价键的形成 ${ }^{[43 \sim 46]}$. 目前用于氰根 测定的方法, 如电位滴定法和常规滴定法, 即耗时又需 要有熟练的操作技巧. 因此, 为了在生产生活中能够方 便地使用并且快速地检测, 已经研制出了很多氧根选择 性传感器. 这些荧光化学传感器提供了非常有吸引力的 特性, 如灵敏度高、选择性强、视觉检测和光学成像等 [47].

一般情况下, 科研工作者按照图 1 所示的三种不同 的识别形式来设计氧根离子的光学传感器. (a)最受欢迎 的策略是识别位点和信号报告单元通过连接臂连接在 一起的传感器. 在这种情况下, 氧根与识别位点的相互 作用会导致信号报告单元的颜色或苂光发生变化. (b)此 外, 还会使用基于配位化合物的置换方法. 在这些传感 器中, 㲵根离子的引入导致了没有配位的指示剂的光谱 行为产生. (c)第三种测定氰根离子的方法被称为化学剂 量法. 这些类型的传感器依赖于一些特殊反应, 一般来 说是与氯根发生不可逆的化学反应.

在氭根传感器发展的初期, 由于大部分传感器都是 有机化合物, 所以科研工作者未考虑研究在水溶液中识 (a)

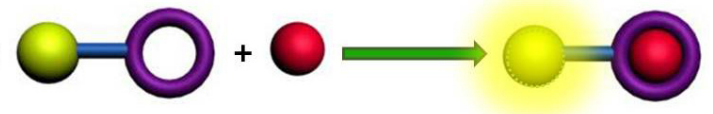

(b)

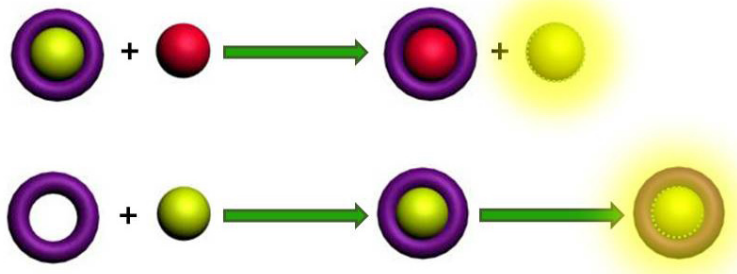

图 1 三种氰根传感器的方法

Figure 1 Three approaches for chemosensors

(a) Chemosensor bearing a signaling subunit as well as a binding site, (b) displacement approach, and (c) chemodosimeter

别氰根离子的传感器, 因此很多传感器分子都是在纯有 机相中进行氰根离子识别的. 然而, 考虑到氰根离子一 般都存在于自然环境中, 并且检测水溶液中的氰根离子 成为一个重要的话题, 所以在之后的工作中, 科研工作 者倾向于研究在含水介质或纯水相中氰根离子的识别 过程, 合成出了很多水溶性的传感器分子. 同时, 固相 传感器具有方便携带等优点, 因此, 有少部分人会研究 氧根离子识别的固相材料. 在本文中, 我们将这几类传 感器分类探讨, 使人们更快捷地理解这些传感器的特 点, 对今后氰根离子传感器的研究提供一定的帮助.

\section{2 氥根离子识别研究进展}

\section{1 纯有机相中的氰根离子识别进展}

2011 年 Wang 等 ${ }^{[48]}$ 设计、合成了新型的基于丙酸纤 维素的苂光化学传感器 $\mathbf{1}$, 用来在 $N, N$-二甲基甲酰胺 (DMF)中检测 $\mathrm{CN}^{-}$. 通过在双氰乙烯基和阴离子之间的 亲核加成反应, 1 对 $\mathrm{CN}^{-}$展示出优于其他常见阴离子的 选择性, 并且可以通过裸眼检测和荧光双通道识别氧 根. 与它的模板化合物相比, 1 成功地展示了其对 $\mathrm{CN}^{-}$ 苂光增强的响应, 它的最低检测限低至 $14 \mathrm{nmol} / \mathrm{L}$, 这 是我们所知道的基于丙酸纤维素的苂光传感的最佳结 果之一. 通过较低的检测极限进一步确认了 1 比模板化 合物有更广泛的线性范围, 更好的竞争选择性，以及 1 更快速的响应.

2012 年 Guo 等 ${ }^{[49]}$ 报道了一个基于香豆素与异柠檬 酸脱氢酶的化合物 $\mathbf{2}$, 它能够在 $\mathrm{CH}_{3} \mathrm{CN}$ 中作为一种被激 活的迈克尔加成型传感器, 用于检测 $\mathrm{CN}^{-}$. 传感器 2 对 $\mathrm{CN}^{-}$的比色和比率苂光响应是由于 $\mathrm{CN}^{-}$与双活性的受 体分子发生迈克尔加成反应，从而阻止了分子内的电荷 转移过程. 传感器在室温下显示了对 $\mathrm{CN}^{-}$的快速反应, 当只有 2 equiv. 的 $\mathrm{CN}^{-}$存在时即达到了最大比率荧光信 号. 此外, 其他阴离子在相同条件下紫外和荧光信号都 
<smiles>[R]C1([R])c2cc(C)ccc2-c2ccc(-c3ccc(C(=C(C#N)C#N)c4ccc(C)cc4)cc3)cc21</smiles>

1<smiles>CCN(CC)c1ccc2c(c1)OCC(C=C1C(=O)c3ccccc3C1=O)=C2</smiles>

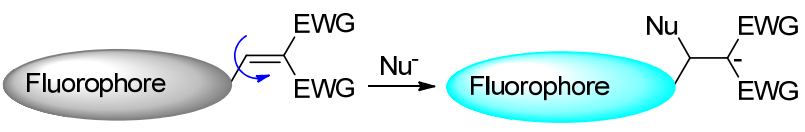

Weak fluorescence Strong fluorescence

EWG = Electron-withdrawing group

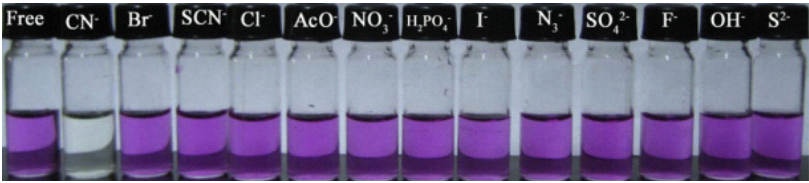

图 2 化合物 2 识别的机制和可见光下溶液照片

Figure 2 Recognition mechanism of compound 2 and the solution image in visible light

没有发生变化, 这表明该传感器对 $\mathrm{CN}^{-}$具有很高的选择
2012 年 Wang 等 ${ }^{[50]}$ 报道了一种能够连续识别两种阴 离子的传感器 $\mathbf{3}$, 在四氢呋喃(THF)中, 传感器 $\mathbf{3}$ 展现出 对 $\mathrm{F}^{-}$和 $\mathrm{CN}^{-}$的高选择性比色响应. 作者提出了阴离子 接力识别的新概念 (ARR), 为阴离子的连续识别提供了 行之有效的方法: 两个阴离子的检测不需要依赖于两个 不同的探针. 巧妙地利用一种探针的固有反应能力, 可 以在一种串联方式中实现双重识别目的.

2012 年 Schmittel 等 ${ }^{[51]}$ 合成了两种基于 1,10 -邻二氮 杂菲-4,7-二甲醛钉配合物 $\mathbf{4}$ 和 $\mathbf{5}$, 两种配合物都能够在 $\mathrm{CH}_{3} \mathrm{CN}$ 中紫外和磷光双通道识别 $\mathrm{CN}^{-}$. 在加入 $\mathrm{CN}^{-}$后 能够裸眼观察到溶液在可见光下由橙红色变为黄色, 在 发光状态下溶液由橙色变成红色. 在室温条件下, 4 和 5 对 $\mathrm{CN}^{-}$的响应速度很快, 只需要理论配比的量就能在 $15 \mathrm{~s}$ 内完成反应. 计算的最低检测限说明这两个传感器 能够在其他离子干扰下检测微摩尔级以下低浓度的 $\mathrm{CN}^{-}$. 由于该配合物具有两个反应位点, 所以能够通过 紫外吸收光谱、磷光光谱和核磁滴定中观察到反应逐步 发生, 并且作者通过理论计算验证了反应是逐步发生 的.

2013 年 Boucekkine 等 ${ }^{[52]}$ 研究了一种高选择性和高 灵敏度的化学传感器 $\mathbf{6}$, 用于在 $\mathrm{CH}_{2} \mathrm{Cl}_{2}$ 中检测微摩尔浓 度的 $\mathrm{CN}^{-}$离子. 当加入 $\mathrm{CN}^{-}$之后溶液发出很强的磷光, 并且对 $\mathrm{CN}^{-}$的选择性要比其它离子高很多. 这种传感器 设计策略可能有助于开发更高效的 “关一开” 磷光传感 器. 性.

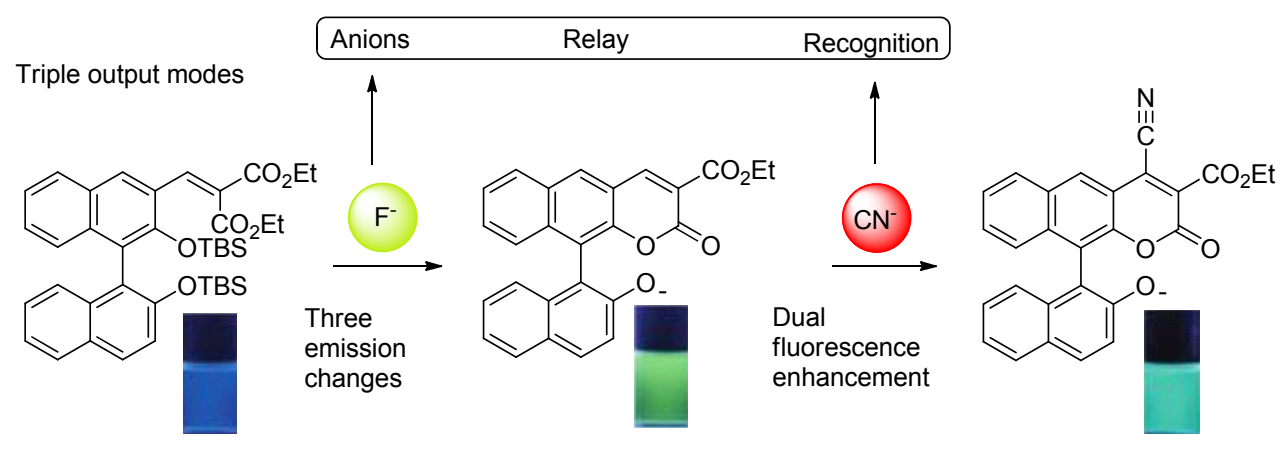

图 3 化合物 3 识别的机制和荧光下溶液照片

Figure 3 Recognition mechanism of compound $\mathbf{3}$ and the solution image under the UV-lamp

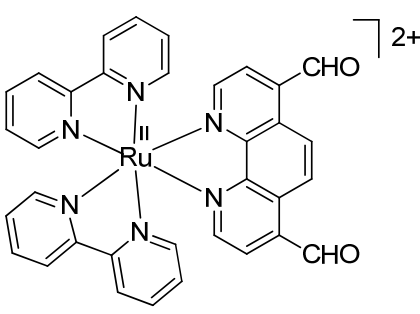

4

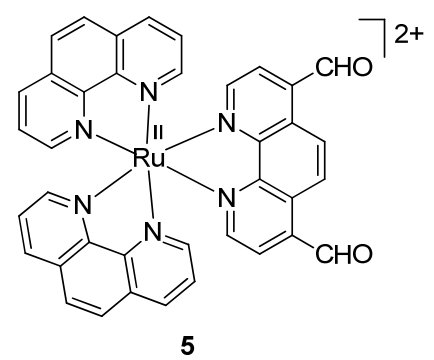




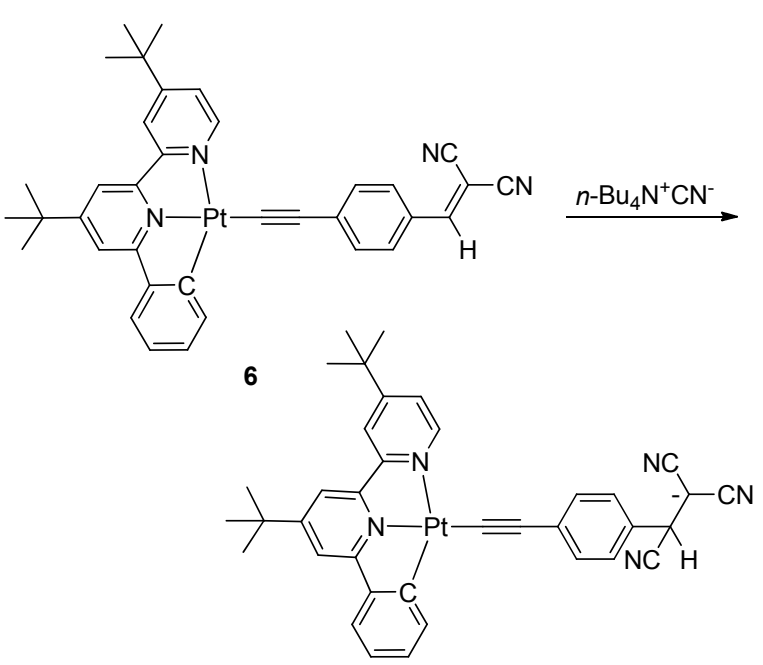

图 4 化合物 $\mathbf{6}$ 的合成过程

Figure 4 Synthetic progress of compound 6

2013 年 Kim 等 ${ }^{[33]}$ 用 4-硝基异硫氰酸酯与二(2-吡啶 甲基)胺合成了一个受体分子 7, 这个分子在质子性溶剂 (如 $\mathrm{EtOH}$ )中对 $\mathrm{CN}^{-}$展现出明显优于其它阴离子的选择 性响应. 此外, 它还通过颜色的变化将 $\mathrm{CN}^{-}$与其他阴离 子区分开来. 它的检测极限远远低于世界卫生组织规定 的饮用水中 $\mathrm{CN}^{-}$含量. 然而, 在诸如乙腈等非质子溶剂 中, 由于强碱性阴离子的非选择性去质子化, 导致了 $\mathrm{CN}^{-}$的选择性较差. 这些结果表明, 受体分子 7 与 $\mathrm{CN}^{-}$ 不同的相互作用机理取决于不同的溶剂.

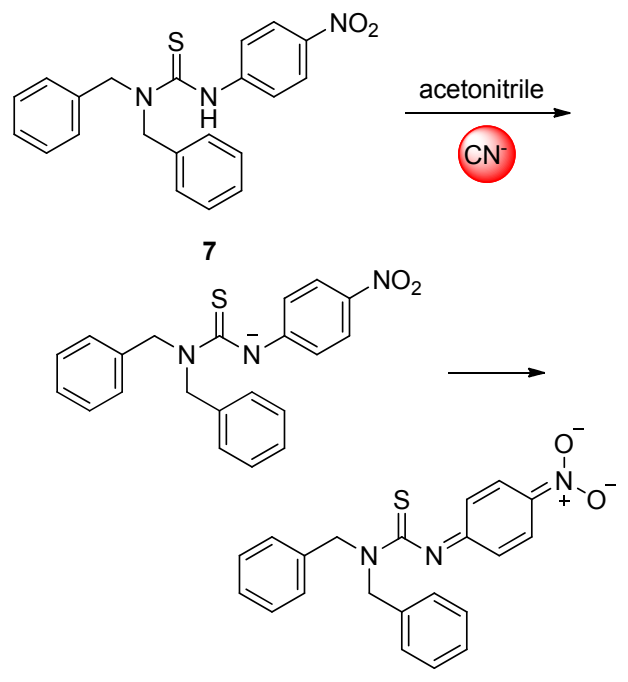

图 5 化合物 7 识别 $\mathrm{CN}^{-}$的示意图

Figure 5 Schematic diagram of compound 7 recogniting $\mathrm{CN}^{-}$

2013 年 Hua 等 ${ }^{[54}$ 设计合成了两种新型的基于 5,10己二基二氢吩嗪的化学传感器 8 和 9 . 其中传感器 8 中 连有两个二氧乙烯基作为结合位点, 传感器 9 中连有一 个二㲵乙烯基和一个醛基, 两个分子中都有吸电子基. 8 展现出分子内电荷转移( ICT) 过程的吸收波长和发射波
长分别在 545 和 $730 \mathrm{~nm}$ 处. 所以当 $\mathrm{CN}^{-}$在 $\mathrm{CH}_{3} \mathrm{CN}$ 中与 8 的两侧发生反应后，它展现出了一个 ICT 阻碍的过程, 从而实现了苂光 “开-关” 的响应. 在传感器 $\mathbf{9}$ 中, 由于 是单边的 ICT 识别过程, 导致 9 对 $\mathrm{CN}^{-}$展现出显著地比 色和近红外的荧光响应. 这两种传感器在其他离子干扰 的情况下, 都对 $\mathrm{CN}^{-}$有高灵敏度和高选择性, 可以用裸 眼观察到明显的光学信号变化.<smiles>CCCCCN1c2ccc(C=C(C#N)C#N)cc2N(CCCCC)c2cc(C=C(C#N)C#N)ccc21</smiles>

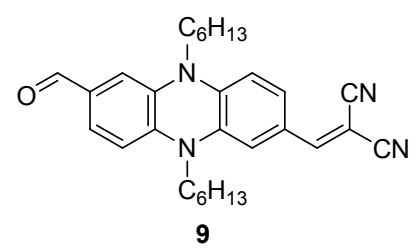

2014 年 Yin 等 ${ }^{[55]}$ 在 EtOH 中将 2-羟基-1,3,5-苯三甲 醛与 1-甲基-2,3,3-三甲基-3H-吲哚通过加热回流的方法 合成了传感器 10. 它的识别能力是在 DMSO 中进行的, 当向 10 中加入多种阴离子后, 只有氧根能够引起荧光 由蓝色-绿色的变化. 它的识别机理是 $\mathrm{CN}^{-}$与吲哚上极 化的 $\mathrm{C}=\mathrm{N}$ 发生亲核加成反应，从而破坏了吲哚和苯环 之间的 $\pi$-共轭体系. 该传感器在 $2 \mathrm{~min}$ 之内就能与 $\mathrm{CN}^{-}$ 反应完全, 最低检测限为 $45 \mathrm{nmol} / \mathrm{L}$.

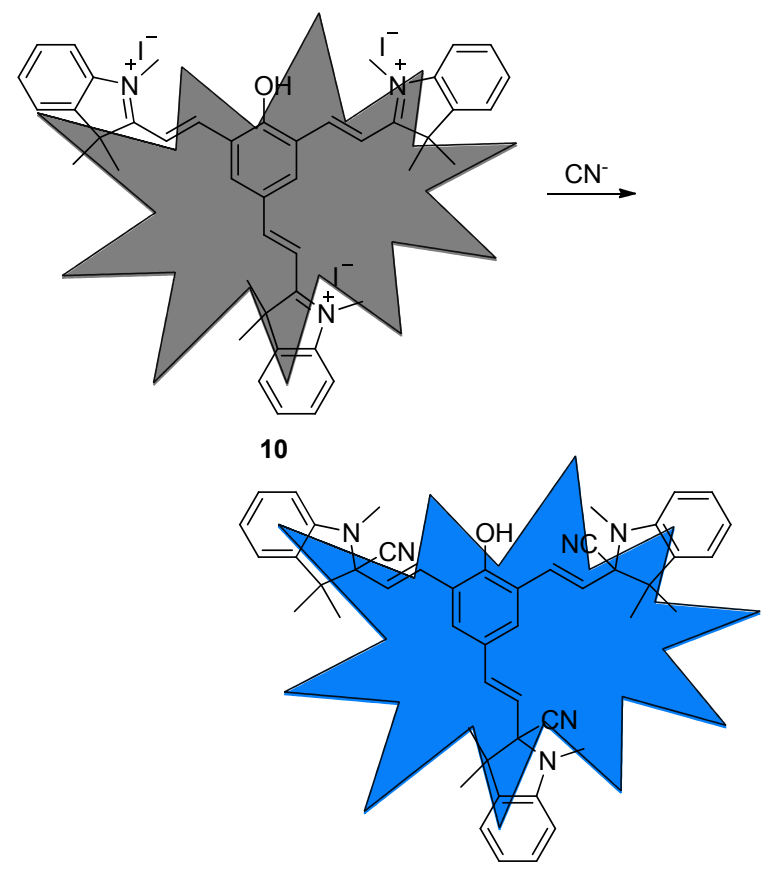

图 6 化合物 10 识别 $\mathrm{CN}^{-}$的机理

Figure 6 Recognition mechanism of compound $\mathbf{1 0}$ 
2015 年 $\mathrm{Wu}$ 等 ${ }^{[56]}$ 报道了一种简单的传感器 $\mathbf{1 1}$, 并对 其在 $\mathrm{CH}_{3} \mathrm{CN}$ 溶液中阳离子和阴离子的传感性能进行了 研究. 传感器 11 可以通过氢键的相互作用比色识别 $\mathrm{F}^{-}$, 并且通过加成反应紫外一苂光双通道选择性地响应 $\mathrm{CN}^{-}$. 传感器 11 对 $\mathrm{F}^{-}$和 $\mathrm{CN}^{-}$离子的最低检测限分别为 0.28 和 0.41. 传感器 11 能够作为潜在的 $\mathrm{F}^{-}$和 $\mathrm{CN}^{-}$传感工具.

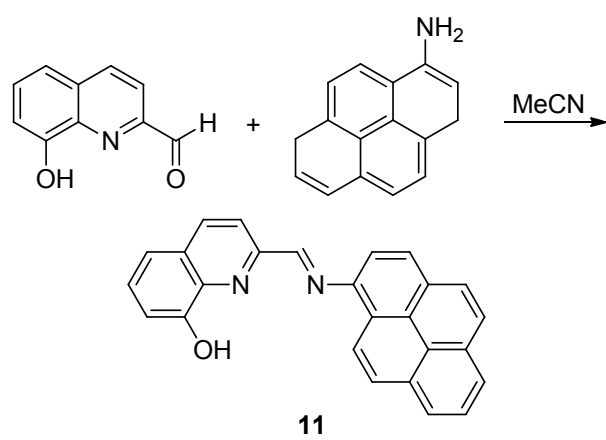

图 7 化合物 $\mathbf{1 1}$ 的合成过程

Figure 7 Synthetic progress of compound $\mathbf{1 1}$

2015 年 Xing 等 ${ }^{[57]}$ 合成了一个凭借分子内电荷转移 (ICT)机理的近红外传感器 12. 该传感器能够在 $\mathrm{CH}_{3} \mathrm{CN}$ 中双比率紫外-荧光检测 $\mathrm{CN}^{-}$. 特别是, 该方法可以通 过检测市售苦杏仁样品中的微量 $\mathrm{CN}^{-}$来追踪测定其 $\beta$ 葡萄糖苷酶的含量.

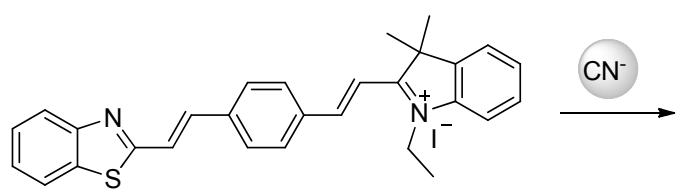

Fluorescence emission at $564 \mathrm{~nm}$

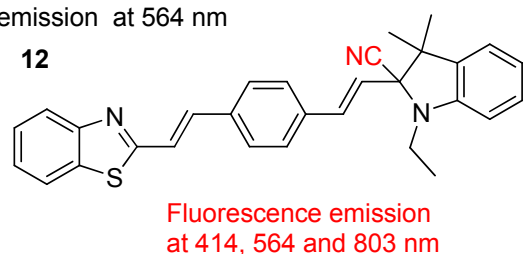

图 8 化合物 $\mathbf{1 2}$ 识别 $\mathrm{CN}^{-}$的机理

Figure 8 Recognition mechanism of compound 12

2016 年 Reddy 等 ${ }^{[58]}$ 合成了一个新型的能够发出磷 光的铱(III)配合物 13. 作者根据众所周知的生成氰醇的 反应，将配合物 13 用于在 $\mathrm{CH}_{3} \mathrm{CN}$ 中检测 $\mathrm{CN}^{-}$, 并且通 过单晶和 X 射线衍射证明了它的固态结构. 值得注意的 是, 铱(III)配合物在固态状态下仍然有很强的红色磷光, 并且在乙腈溶液中也有红色光发出. 作者通过紫外和磷 光验证了 $\mathrm{CN}^{-}$与铱(III)配合物的结合方式. 当加入 2 equiv. $\mathrm{CN}^{-}$之后, 溶液明显地从橙色变到了黄色, 并且 发出的磷光由红色变成蓝色. 作为识别实验的重要一部 分，基于配合物 13 的试纸也被制作出来用于检测 $\mathrm{CN}^{-}$.

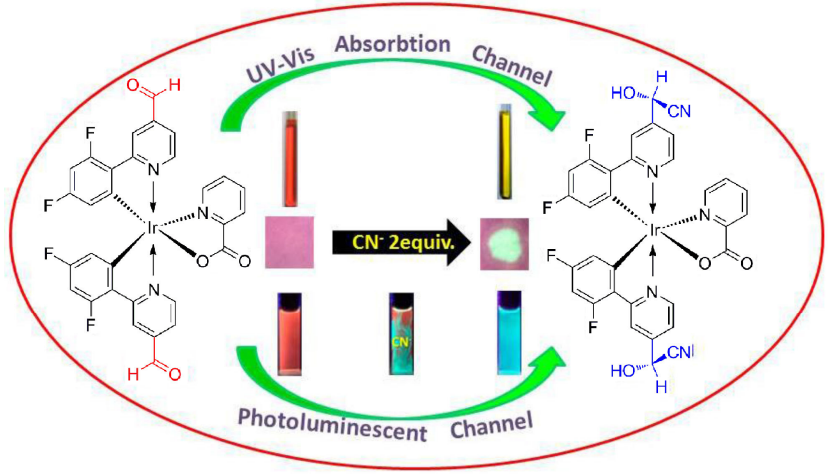

图 9 化合物 13 识别 $\mathrm{CN}^{-}$的机理

Figure 9 Recognition mechanism of compound $\mathbf{1 3}$

2016 年 Volpi ${ }^{[59]}$ 报道了一个在狮三酮溶液中检测苦 杏仁中 $\mathrm{HCN}$ 的传感器 $\mathbf{1 4}$. 这一过程是基于将 $\mathrm{HCN}$ 从切 碎的苦杏仁种子中吸收到狮三酮或氨水铜配合物溶液 中. 作者还利用定性实验证明了在苦杏仁种子中存在 $\mathrm{HCN}$, 并将 $\mathrm{HCN}$ 还原形成一种有趣的混合价铜氨基氰 化复合物 $\mathrm{Cu}_{3}\left(\mathrm{NH}_{3}\right)_{4}(\mathrm{CN})_{4}$.
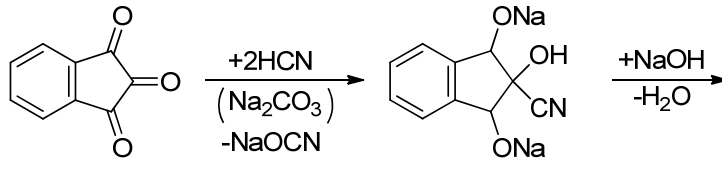

ninhydrin red colored compound

14<smiles>NCC1(O)C(O)c2ccccc2C1O</smiles>

blue colored compound

图 10 化合物 14 识别 $\mathrm{CN}^{-}$的机理

Figure 10 Recognition mechanism of compound 14

2016 年 $\mathrm{Liu}$ 等 ${ }^{[60]}$ 设计并合成了一种新颖的双位点 控制分子内电荷转移-光诱导电子转移-苂光共振能量 转移(ICT-PET-FRET)的传感器 $\mathbf{1 5}$, 它在 THF 中显示出 对 $\mathrm{CN}^{-}$的高选择性苂光和比色识别. 传感器 15 中 $\mathrm{NH}$ 和 $\mathrm{CH}$ 通过延长的骨架连接在一起，同时，它们被用作 两个结合位点, 并且通过光诱导电子转移和分子内电荷 转移控制了菜二甲酰亚胺的苂光. 基于传感器 15 的检 测试纸证明了在固态下仍然对 $\mathrm{CN}^{-}$展现出良好的响应.

2016 年 Wang 等 ${ }^{[61]}$ 合成了四苯基二烯(TPE)和二酮 吡咯(DPP)两种共轭结构 16 和 17, 并且研究了它们的荧 光性质. 化合物 16 和 17 无论在溶液中还是固态下都发 出很强的苂光. 其中 17 在 THF 中展示出对 $\mathrm{CN}^{-}$的高选 择性和特异性响应，使溶液颜色由粉色变为无色，发射 出的亮红色磷光猝灭. 它的苂光最低检测限是 0.3 $\mu \mathrm{mol} \cdot \mathrm{L}^{-1}$, 远低于世界卫生组织规定的 $1.9 \mu \mathrm{mol} \cdot \mathrm{L}^{-1}$ 的 标准. 


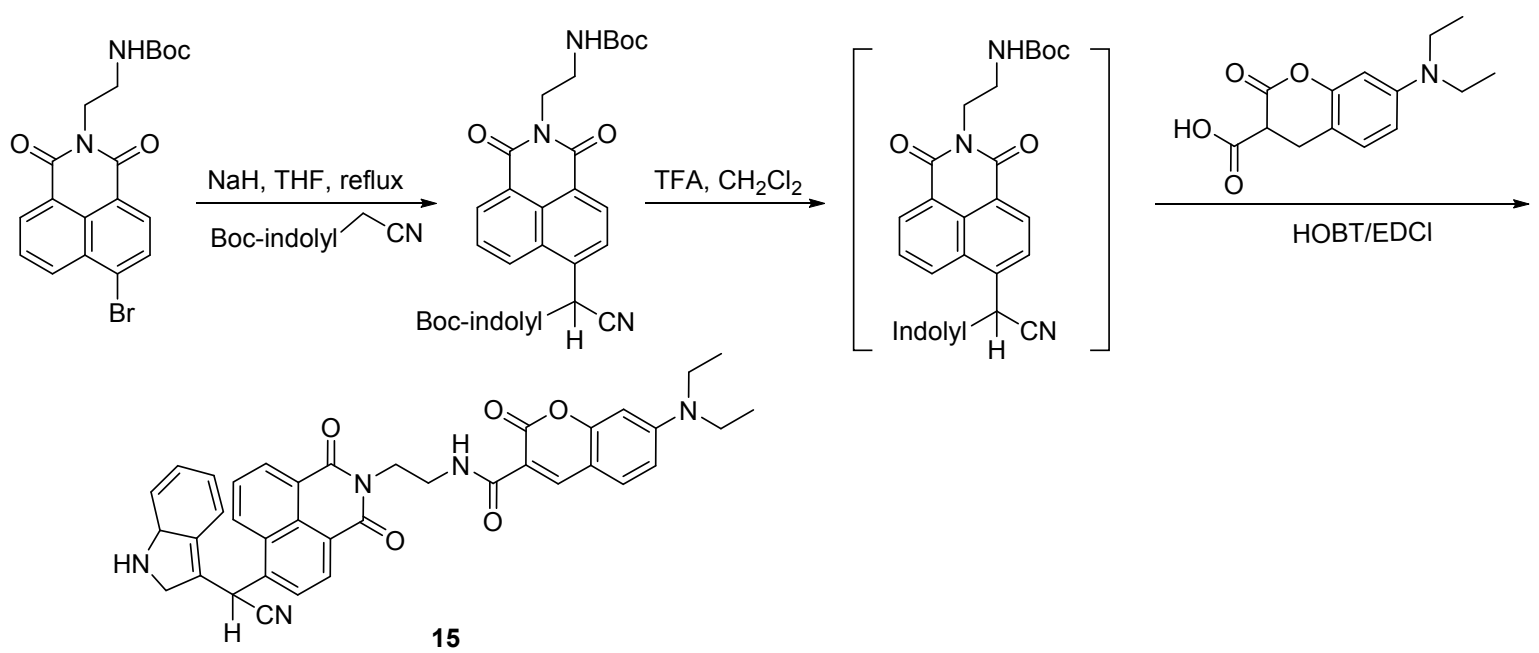

图 11 化合物 15 的合成过程

Figure 11 Synthetic progress of compound 15
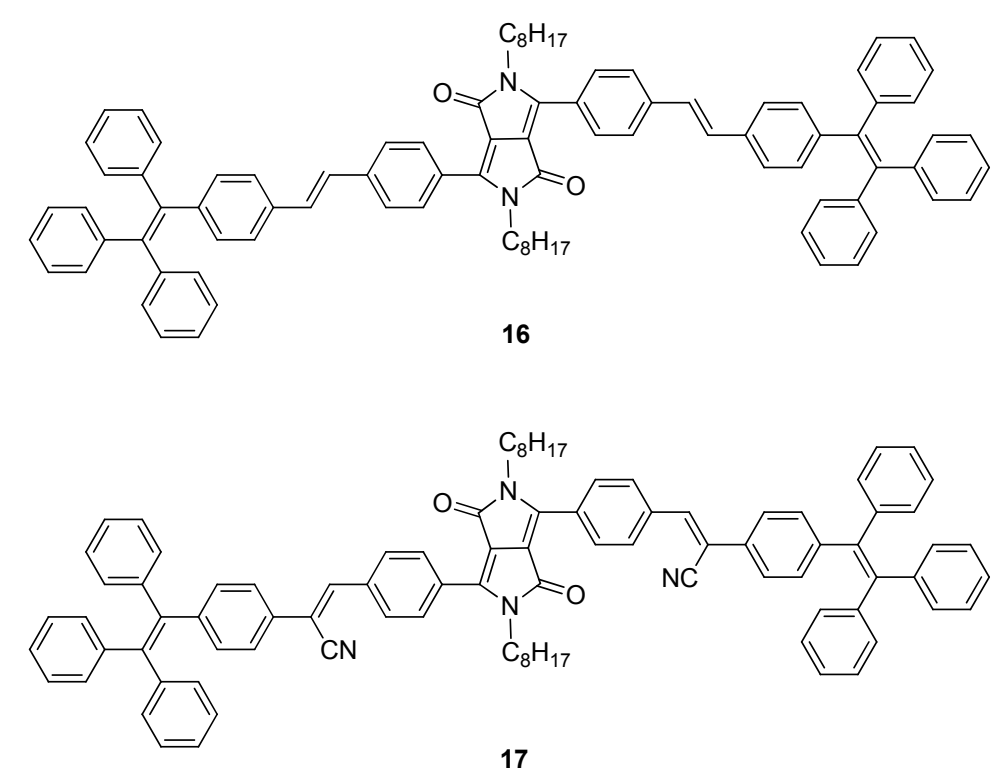

2017 年 Yin 等 ${ }^{[2]}$ 设计了一种新型的发红光材料 18, 它是基于异环己烯酮骨架的典型非对称 $\pi$-共轭结构, 能 在 $\mathrm{EtOH}$ 中与 $\mathrm{CN}^{-}$发生亲核加成反应, 并且没有受到其 他阴离子的干扰. 在该传感器中以基于异环己烯酮骨架 的醛为信号报告基团, 这是第一次将这类骨架作为信号 报告基团, 用作化学传感器来检测其它物质.

此外, 作者还证明了这种独特的传感器在活细胞中 检测 $\mathrm{CN}^{-}$的能力.

\section{2 在含水介质中的氭根离子识别进展}

2011 年 $\mathrm{Li}$ 等 ${ }^{[63]}$ 合成了一个铱(III)配合物 19, 它的 纳米晶体证明了它能够在 $\mathrm{DMF} / \mathrm{H}_{2} \mathrm{O}(V: V=9: 1)$ 溶液 中和活的海拉细胞中用作 $\mathrm{CN}^{-}$比率传感器. 通过抑制纳 米晶体中的苂光共振能量转移(FRET)过程, 配合物 19

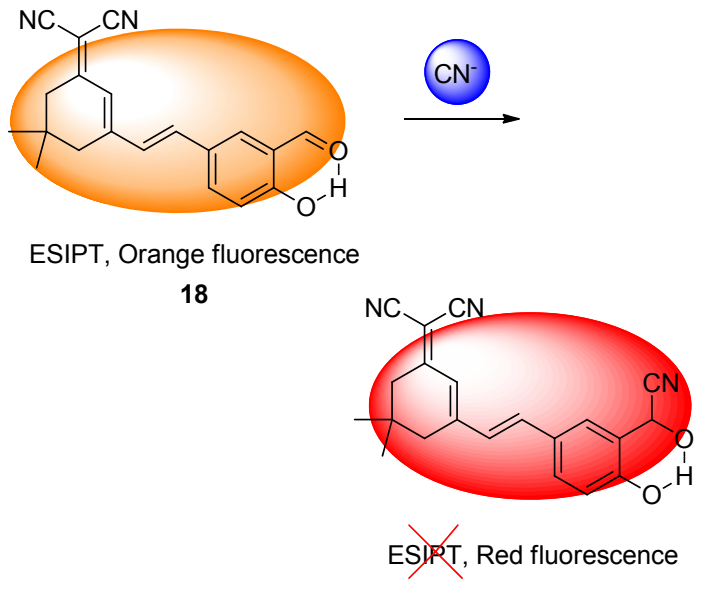

图 12 化合物 18 识别 $\mathrm{CN}^{-}$的机理

Figure 12 Recognition mechanism of compound 18 能够对 $\mathrm{CN}^{-}$表现出明显优于其他阴离子的选择性. 0.18 
$\mu \mathrm{mol} / \mathrm{L}$ 的最低检测限使配合物 19 能成功地检测饮用水 中的 $\mathrm{CN}^{-}$. 此外, 通过激光扫描上转换发光显微成像 (LSUCM) 实验, 证明了 19 的纳米晶体可以作为一种用 于在活细胞中实时监测 $\mathrm{CN}^{-}$的比率传感器. 据我们所知 道的, 这个方法能够成为一个阴离子传感和生物成像研 究的模板.
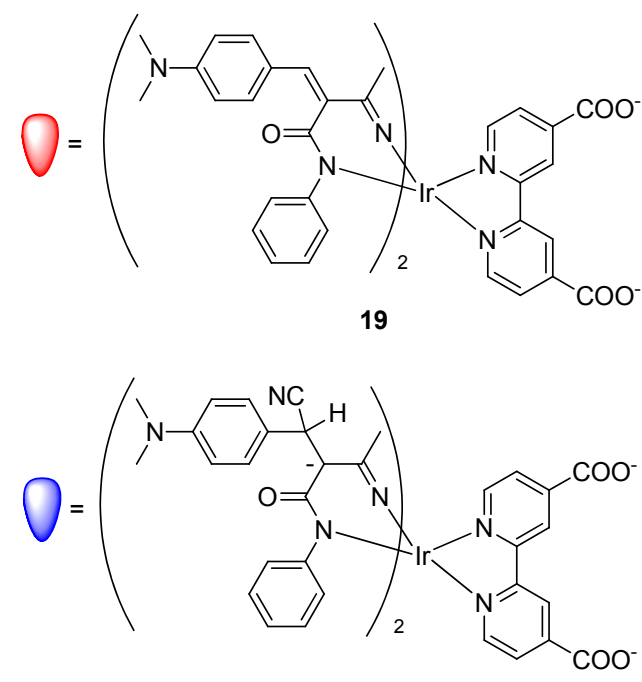

$19-\mathrm{CN}^{-}$

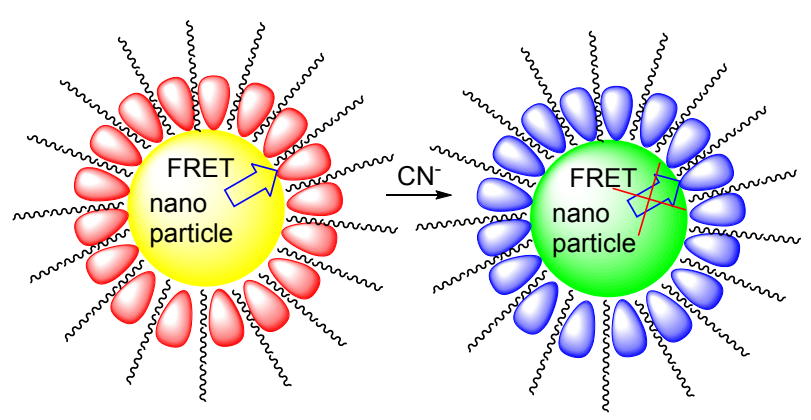

图 13 纳米粒子 19 识别 $\mathrm{CN}^{-}$的机理

Figure 13 Recognition mechanism of nanoparticle 19

2012 年 $\mathrm{Kim}$ 等 ${ }^{[64]}$ 报道了用贝利斯- 希尔曼冷凝反应 将 $\alpha, \beta$-不饱和酮功能化的菜并吡喃化合物 $\mathbf{2 0}$, 被用作在 DMSO/HEPES $(V: V=5: 5, \mathrm{pH}=7.0)$ 缓冲溶液中作为 $\mathrm{CN}^{-}$苂光传感器. 传感器对 $\mathrm{CN}^{-}$显示了优于其他阴离子 的选择性和灵敏度, 它通过与 $\mathrm{CN}^{-}$发生迈克尔加成反应 以及随后发生的一个 $1,3-\sigma$ 单键重排反应进行 $\mathrm{CN}^{-}$识别. 当加入 $\mathrm{CN}^{-}$以后, 观察到明显的比率荧光变化, 达到了 裸眼检测微摩尔 $\mathrm{CN}^{-}$的效果.

2013 年 Lee 等 ${ }^{[65]}$ 发现氢键促进共价修饰在小分子 化学合成和检测中有着广泛的应用. 作者合成了一个基 于氧杂葱的苂光传感器 21 , 分子内的凹面存在着多重 氢键, 这些氢键紧紧地将酰基和醛基固定住. 这种给 体一受体间氢键的结合形式使分子内键的旋转有巨大的
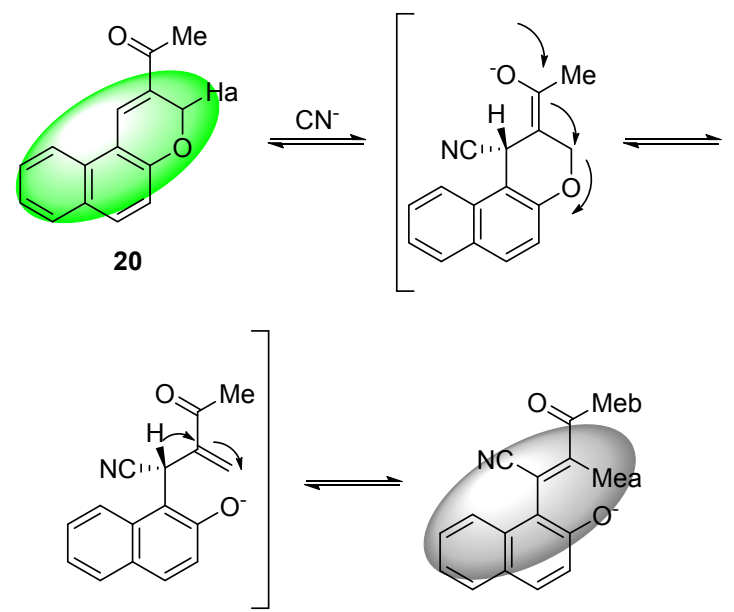

图 14 化合物 20 识别 $\mathrm{CN}^{-}$的机理

Figure 14 Recognition mechanism of compound 20

能量屏障，有效地帮助分子形成巨大的凹面，并有效地 使极化的亲电性羰基被亲核的 $\mathrm{CN}^{-}$进攻，使 $\mathrm{CN}^{-}$在 $\mathrm{CH}_{3} \mathrm{CN} / \mathrm{HEPES}(\mathrm{V}: V=1: 9, \mathrm{pH}=7.0)$ 缓冲溶液中发生 亲核进攻. 被 $\mathrm{CN}^{-}$进攻加成之后, 传感器 21 在 $400 \mathrm{~nm}$ 处有一个明显的荧光增强的现象，并且该反应发生得非 常快, 实现了实时检测 $\mathrm{CN}^{-}$的效果.
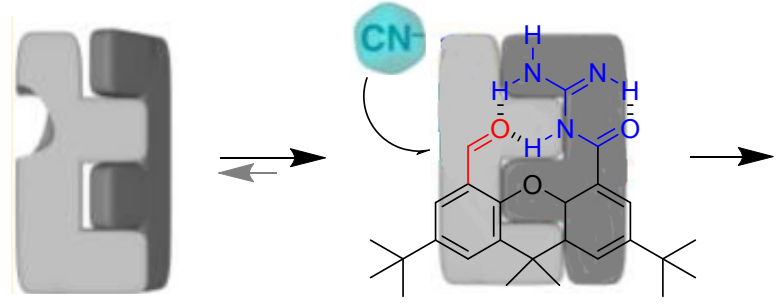

21

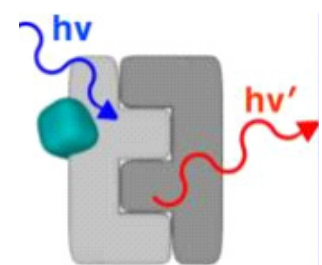

图 15 化合物 21 识别 $\mathrm{CN}^{-}$的机理

Figure 15 Recognition mechanism of compound 21

2013 年 Aprahamian 等 ${ }^{[66]}$ 合成了一个三唑吡啶盐用 来在 $\mathrm{DMSO} / \mathrm{H}_{2} \mathrm{O}(V: V=99: 1)$ 溶液中作为高效的反应 型 $\mathrm{CN}^{-}$传感器 22. 当向传感器 22 中加入 $\mathrm{NaCN}$ 后, 能 够观察到荧光发射强度增加了近 60 倍, 并且其最低检 测限为 0.2 . 当 $\mathrm{CN}^{-}$与传感器 22 发生亲核加成反应后, 桥连的氮发生开环反应，使光学信号发生变化，从而展 现出传感器 22 对 $\mathrm{CN}^{-}$独特的检测性能, 作者利用密度 泛函理论计算证明了这个开环反应的发生，同时，将该 实验的反应条件进一步优化以便在实际应用中使用该 方法. 


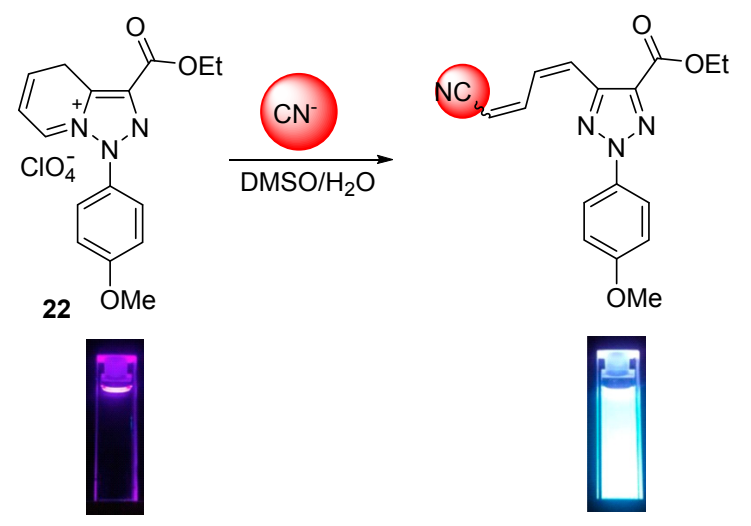

图 16 化合物 22 识别 $\mathrm{CN}^{-}$的机理.

Figure 16 Recognition mechanism of compound 22

2014 年 Chen 等 ${ }^{[67]}$ 报道了一个新型的基于二氧乙烯 基团的荧光传感器 23 , 它是基于激发态分子内电荷转 移一激发态分子内质子转移(ESICT-ESIPT) 两个效应偶 合的体系. 基于这个偶和体系, 该传感器能够在 THF/ HEPES $(V: V=8: 2, \mathrm{pH}=7.3)$ 溶液中对 $\mathrm{CN}^{-}$展现出特 殊的选择性和灵敏性. 在与 $\mathrm{CN}^{-}$反应后, 能够观察到紫 外吸收光谱有一个 $96 \mathrm{~nm}$ 的蓝移过程, 并且用肉眼能够 观察到溶液由黄色变为无色, 红色苂光猝灭. 作者利用 密度泛函理论计算和时间响应证明了该反应的机理. 此 外, 基于传感器 23 的试纸很容易制造且成本很低, 试纸 可以被用作实用的、有效的 $\mathrm{CN}^{-}$检测工具.

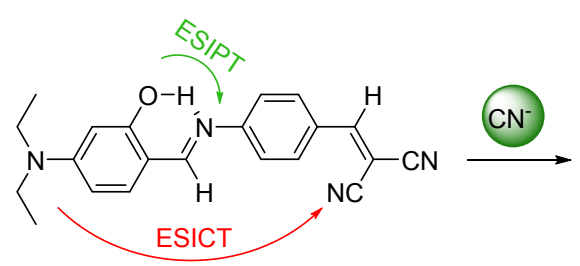

23

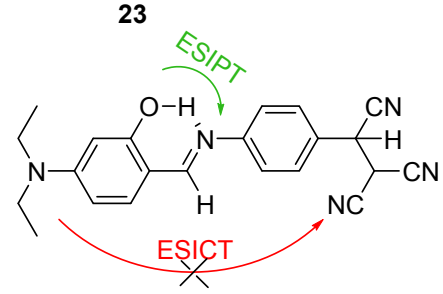

图 17 化合物 $\mathbf{2 3}$ 识别 $\mathrm{CN}^{-}$的机理

Figure 17 Recognition mechanism of compound $\mathbf{2 3}$

2014 年 Kumar 等 ${ }^{[68]}$ 设计合成了基于六苯基苯的聚 集态荧光增强活性的传感器 24, 用于在 $\mathrm{H}_{2} \mathrm{O} / \mathrm{EtOH}(V$ : $V=8: 2$ ) 溶液中选择性检测 $\mathrm{CN}^{-}$离子. 通过 $\mathrm{CN}^{-}$于分子 中高度缺电子的酰胺发生亲核加成反应生成 $\mathrm{CN}^{-}$加成 产物, 导致比色和比率苂光发生变化. 利用基于 $\mathbf{2 4}$ 的试 纸检测出最低检测限为 $2.6 \mathrm{ng} / \mathrm{cm}^{2}$, 为在水介质中实时 检测 $\mathrm{CN}^{-}$提供了一种简单且低成本的方法. 同时, 传感 器 24 在检测 $\mathrm{CN}^{-}$后继续加入三氟乙酸, 能重新释放出
主体. 作者将这种循环制作出一个逻辑门，只有恰当地 输入顺序才能有正确的信号输出.

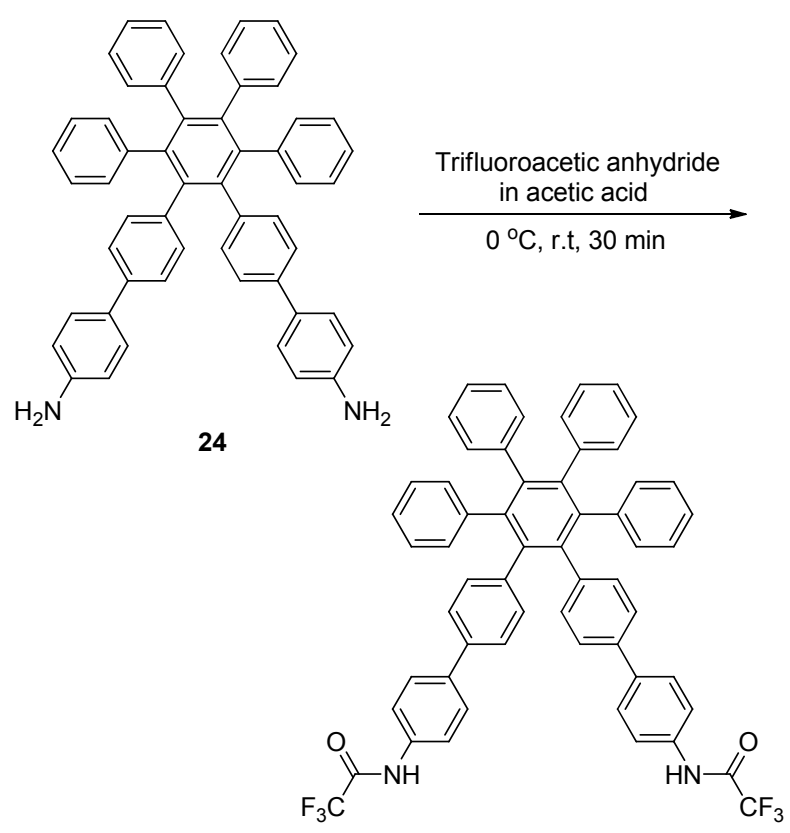

图 18 化合物 24 的合成过程

Figure 18 Synthetic progress of compound $\mathbf{2 4}$

2014 年我们课题组 ${ }^{[69]}$ 报道了一个基于萘胺和二羟 基萗甲醛的低成本苂光传感器 $\mathbf{2 5}$, 它在 DMSO/HEPES $(V: V=8: 2, \mathrm{pH}=7.2)$ 溶液中苂光打开检测 $\mathrm{CN}^{-}$. 当用 $365 \mathrm{~nm}$ 紫外灯照射时, 肉眼观察到溶液的苂光变成亮 蓝色, 并且其它常见阴离子没有干扰传感器 25 与 $\mathrm{CN}^{-}$ 的反应，它的最低检测限为 $8.434 \times 10^{-9} \mathrm{~mol} \cdot \mathrm{L}^{-1}$. 该识 别过程是通过 $\mathrm{CN}^{-}$与传感器分子发生亲核加成反应, 随 后又通过氢键形成了二聚体，导致荧光增强，并且通过 FT-IR、ESI/MS 和 ${ }^{1} \mathrm{H}$ NMR 滴定等验证了这一机理.

2014 年 Wang 等 ${ }^{[70]}$ 报道了一个由吡咯并吡咯二酮和 二氢化狮的苂光传感器 $\mathbf{2 6}$, 被用于检测水溶液中的 $\mathrm{CN}^{-}$. 当在传感器 26 的 THF 溶液中加入 $\mathrm{CN}^{-}$的水溶液, 能发生迈克尔加成反应, 导致溶液快速地从紫色变到黄 色, 紫外吸收峰也从 $553 \mathrm{~nm}$ 蓝移至 $480 \mathrm{~nm}$, 与此同时, 其它阴离子并没有导致任何变化. 此外，在 484 和 572 $\mathrm{nm}$ 处的磷光强度也明显的发生变化. 利用苂光滴定实 验计算得出其最低检测限为 $0.36 \mu \mathrm{mol} \cdot \mathrm{L}^{-1}$. 结果表明, 26 可以作为双通道、高选择性、即时性和敏感的 $\mathrm{CN}^{-}$ 检测工具.

2015 年 Chen 等 ${ }^{[71]}$ 合成并表征了一个基于 7 -氮杂吲 哚的低成本的分子量小的化合物 27, 把 1-甲基-7-氮杂 吲哚上的醛基用双氰乙烯基取代来作为一个电子给体 和识别位点. $\mathrm{CN}^{-}$对双氰乙烯基的亲核加成导致了荧光 强度发生明显的变化, 能够在 THF/HEPES $(V: V=9$ : 
<smiles>O=C1C=Cc2ccccc2C1=CNc1ccc2ccccc2c1</smiles>

$\mathrm{R}$<smiles>CC12C=Cc3ccccc3C1=CN(c1ccc3ccccc3c1)CO2</smiles>

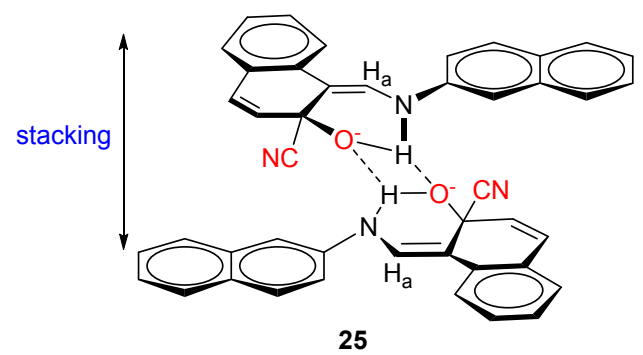

图 19 化合物 25 识别 $\mathrm{CN}^{-}$的机理

Figure 19 Recognition mechanism of compound 25

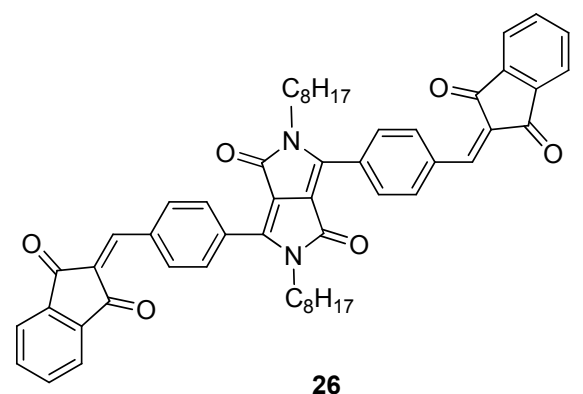

$1, \mathrm{pH}=7.3$ ) 溶液中比率苂光检测 $\mathrm{CN}^{-}$. 其中, 激发状态 分子内电荷转移(ESICT)机理在传感过程中起着关键作 用, 该机理得到了密度函数理论和时间相关密度函数理 论计算的支持. 此外, 含有传感器分子的试纸很容易被 制造出来, 并为 $\mathrm{CN}^{-}$离子提供了一个低成本、实用和有 效的检测工具.

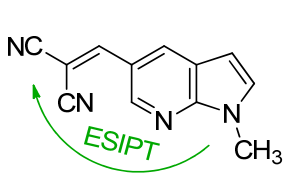

27

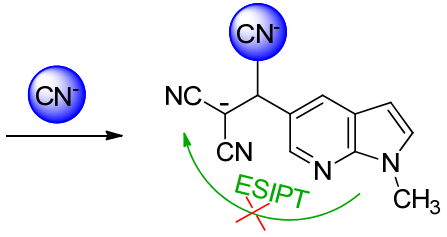

27- $\mathrm{CN}^{-}$
图 20 化合物 $\mathbf{2 7}$ 识别 $\mathrm{CN}^{-}$的机理

Figure 20 Recognition mechanism of compound 27

2015 年我们课题组 ${ }^{[72]}$ 基于分子内电荷转移机理, 通过一种绿色化学的方法, 设计并合成了一种易于制作 的传感器 28, 该传感器在室温下 DMSO/HEPES $(V$ : $V=2: 8, \mathrm{pH}=7.26)$ 中实现了双通道即时检测 $\mathrm{CN}^{-}$. 通
过实验表明, 传感器 $\mathbf{2 8}$ 通过亲核加成反应识别 $\mathrm{CN}^{-}$, 并 且其它阴离子的存在并没有影响到 $\mathrm{CN}^{-}$的识别, 对 $\mathrm{CN}^{-}$ 的最低检测限为 $2.7 \times 10^{-7} \mathrm{~mol} \cdot \mathrm{L}^{-1}$, 满足了在生理和环 境系统中检测 $\mathrm{CN}^{-}$的标准. 此外，自制的基于 $\mathbf{2 8}$ 的试纸 对 $\mathrm{CN}^{-}$显示出了良好的选择性, 证明这些试纸可以作为 方便和有效的 $\mathrm{CN}^{-}$检测工具.<smiles>CN(C)c1ccc(C=C(C#N)C#N)cc1</smiles>

28

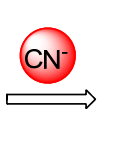<smiles>CN(C)c1ccc(C(C#N)C(C#N)C(C#N)C(C)(C)C)cc1</smiles>

图 21 化合物 28 识别 $\mathrm{CN}^{-}$的机理

Figure 21 Recognition mechanism of compound 28

2015 年 Chow 等 ${ }^{[73]}$ 合成并且表征了一个新型的双 金属 $\mathrm{Cu}-\mathrm{Fe}$ 配合物 29, 这个配合物被证明是一个多功能 的分子, 同时具有化学传感的功能. 在 DMF/HEPES $(V: V=1: 1, \mathrm{pH}=7.4)$ 溶液中, $\mathrm{CN}^{-}$可以将其催化-氧 化, 并且导致光信号变化. 研究结果表明, 配合物 29 能 在三个方面提供良好的性能. (1)在含水体系中专门作为 $\mathrm{CN}^{-}$的裸眼比色传感器; (2) $\mathrm{CN}^{-}$的最低检测限降低了大 约 80 倍(从 32 到 $0.4 \mu \mathrm{mol} / \mathrm{L}$ ); (3)氰化物被完全氧化, 形 成了更安全的、稳定的氰酸盐离子 $\left(\mathrm{OCN}^{-}\right)$. 这种检测性 质能够被应用于检测真实水体中的 $\mathrm{CN}^{-}$, 如河流、湖泊 和地下水, 它对 $\mathrm{CN}^{-}$有较高的回收率和良好的相对标准 偏差.

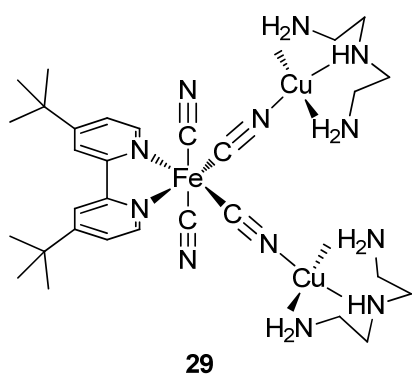

2016 年我们课题组 ${ }^{[74]}$ 设计并合成了一种新型基于 柱[5]芳烃的化学传感器 30, 它利用了 8-差弪喹啉部分作 为一个结合位点和信号报告单元. 通过一个新型的 $\mathrm{CN}^{-}$ 诱导的自组装机理, 这个基于柱[5]芳烃的传感器能够 在 $\mathrm{DMSO} / \mathrm{H}_{2} \mathrm{O}(V: V=8: 2)$ 高灵敏度和选择性的检测 $\mathrm{CN}^{-}$. 当将 $\mathrm{CN}^{-}$加入到传感器的溶液中时, 出现了一种 强烈的黄绿色荧光, 苂光的最低检测限为 $1.08 \times 10^{-8}$ $\mathrm{mol} \cdot \mathrm{L}^{-1}$. 此外, 基于传感器的试纸被制作出来, 这种化 学传感器试纸是一种很好 $\mathrm{CN}^{-}$检测工具. 随后, 我们还 对生命体系中的应用进行了研究, 该传感器也可以在发 芽的土豆中检测 $\mathrm{CN}^{-}$. 值得一提的是, $\mathrm{CN}^{-}$诱导的自组 装机理是一种新型的传感器设计方法. 


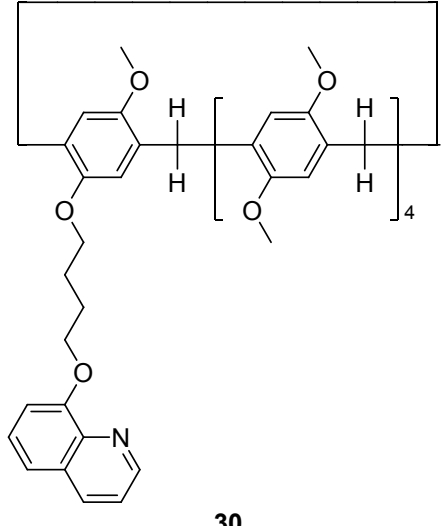

30

2016 年 Son 等 ${ }^{[75]}$ 设计和合成了两种基于萘酰亚胺 的新型分子 31 和 32 . 在这两个分子中, 双氧乙烯基部 分和氰基乙氧羰基乙烯基部分分别作为识别位点与吸 电子基的芸酰亚胺环苂光团相结合. 在 $\mathrm{THF} / \mathrm{H}_{2} \mathrm{O}(V$ : $V=3: 7$ ) 溶液中, 即使在存在其它干扰的情况下, 这两 种受体都能表现出对 $\mathrm{CN}^{-}$高度的灵敏性和选择性, 可以 通过肉眼观察到有明显的反应信号. 作者利用荧光光 谱、核磁共振滴定和高分辨率质谱等技术合理地解释了 这两个传感器分子识别 $\mathrm{CN}^{-}$的机理. 在加入 $\mathrm{CN}^{-}$之后, 31 和 32 的苂光都明显增强了. 与 32 相比, 31 展现出对 $\mathrm{CN}^{-}$更高的亲和性和灵敏度.
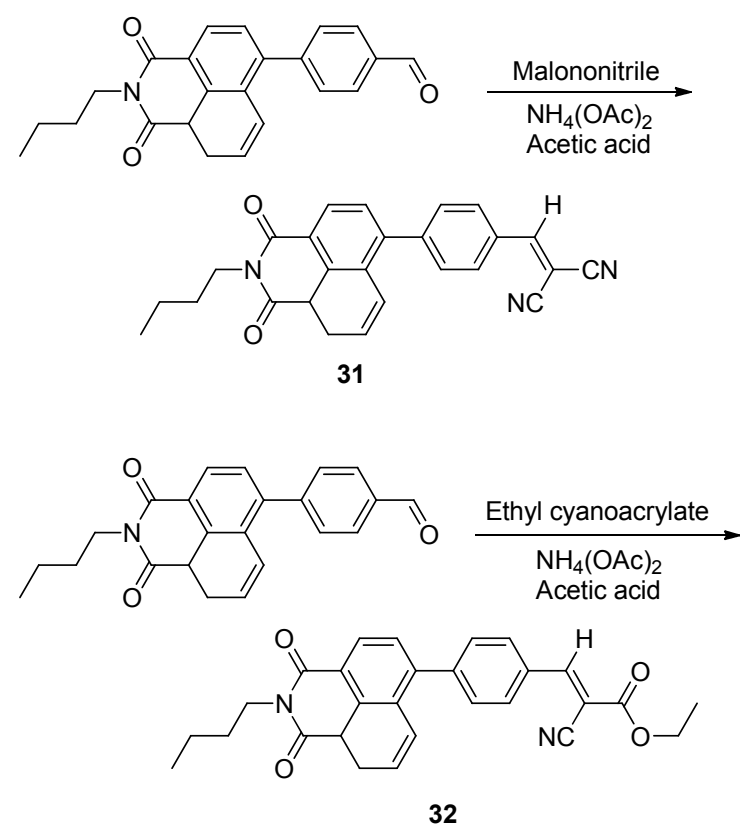

图 22 化合物 $\mathbf{3 1}$ 和 $\mathbf{3 2}$ 的合成过程

Figure 22 Synthetic progress of compounds $\mathbf{3 1}$ and $\mathbf{3 2}$

2016 年 Ghosh 等 ${ }^{[76]}$ 用 2-羟基萗甲醛和 2,3-二氨基 顺丁烯二腈反应合成了相应的双席夫碱衍生物 33. 传 感器 33 的 $\mathrm{Zn}^{2+}$ 配合物在 $\mathrm{DMSO} / \mathrm{H}_{2} \mathrm{O}(V: V=7: 3$, $\mathrm{pH}=7.2$ ) 的三羟甲基氨基甲烷缓冲溶液中显示了与
$\mathrm{CN}^{-}$的选择性结合, 其紫外-可见和荧光光谱都有显著 的变化. 并且由紫外光谱能够看出, 当 $33-\mathrm{Zn}$ 与 $\mathrm{CN}^{-}$反 应后, 会将传感器 33 重新释放出来. $\mathrm{CN}^{-}$与 33 的核磁滴 定证明没有反应前, 分子中的两个羟基以氢键相互作 用, 之后以双齿配位基的方式相互作用. 将传感器用硅 胶薄层色谱法(TLC)浸泡后, 再滴加 $\mathrm{CN}^{-}$, 能够看到其 颜色明显的由黄色变为橙色. 在环境和分析化学中, 可 以利用它作为潜在的工具来检测有毒的 $\mathrm{CN}^{-}$离子. 传感 器 33 可以被用作检测仓鼠幼㩄的肾细胞中 $\mathrm{CN}^{-}$吸收量 的一种成像试剂.
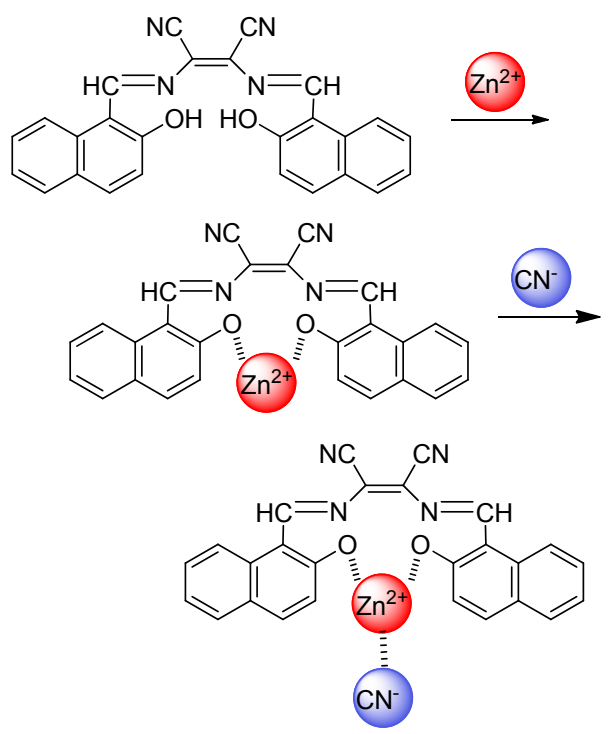

图 23 化合物 33 识别 $\mathrm{CN}^{-}$的机理

Figure 23 Recognition mechanism of compound $\mathbf{3 3}$

2016 年我们课题组 ${ }^{[77]}$ 设计并合成了一种基于咪唑 并吩嗪的双通道传感器 $\mathbf{3 4}$, 传感器 34 可以在 $\mathrm{DMSO} /$ $\mathrm{H}_{2} \mathrm{O}(V: V=7: 3)$ 水溶液中连续检测 $\mathrm{CN}^{-}$和 $\mathrm{HSO}_{4}^{-}$, 并 具有较高的选择性和灵敏度. 在加入了 $\mathrm{CN}^{-}$的水溶液 后, 直接可以看见传感器 34 的溶液从黄色到橙色的颜 色变化, 同时, 传感器的黄色荧光被猝灭. 更有趣的是, 将 $\mathrm{HSO}_{4}^{-}$加入到包含 $\mathrm{CN}^{-}$的传感器水溶液后, 比色和荧 光都可以恢复, 其他的阴离子不能引起类似的反应. 34 和 34- $\mathrm{CN}$ 分别对 $\mathrm{CN}^{-}$和 $\mathrm{HSO}_{4}^{-}$的最低检测限为 $8.9 \times 10$ ${ }^{-8}$ 和 $1.46 \times 10^{-10} \mathrm{~mol} \cdot \mathrm{L}^{-1}$. 值得注意的是, 基于传感器 34 的试纸具有连续响应水溶液中的 $\mathrm{CN}^{-}$和 $\mathrm{HSO}_{4}^{-}$的功 能, 为阴离子的连续识别提供了一种简便方法.

2017 年 El-Shishtawy 等 ${ }^{[78]}$ 合成了一种新的吩噻嗪 衍生物 35, 它含有两个二㲵乙烯基, 来作为两个 $\mathrm{CN}^{-}$的 反应位点, 并得到了充分的表征. 传感器 35 在 $\mathrm{CH}_{3} \mathrm{CN} /$ $\mathrm{H}_{2} \mathrm{O}(V: V=1: 1)$ 溶液中存在一个分子内电荷转移的 吸收带 $(494 \mathrm{~nm})$ 和荧光发射带 $(633 \mathrm{~nm})$. 用不同浓度的 $\mathrm{CN}^{-}$离子滴定时, 吸收峰和发射峰均以一种比率的方 


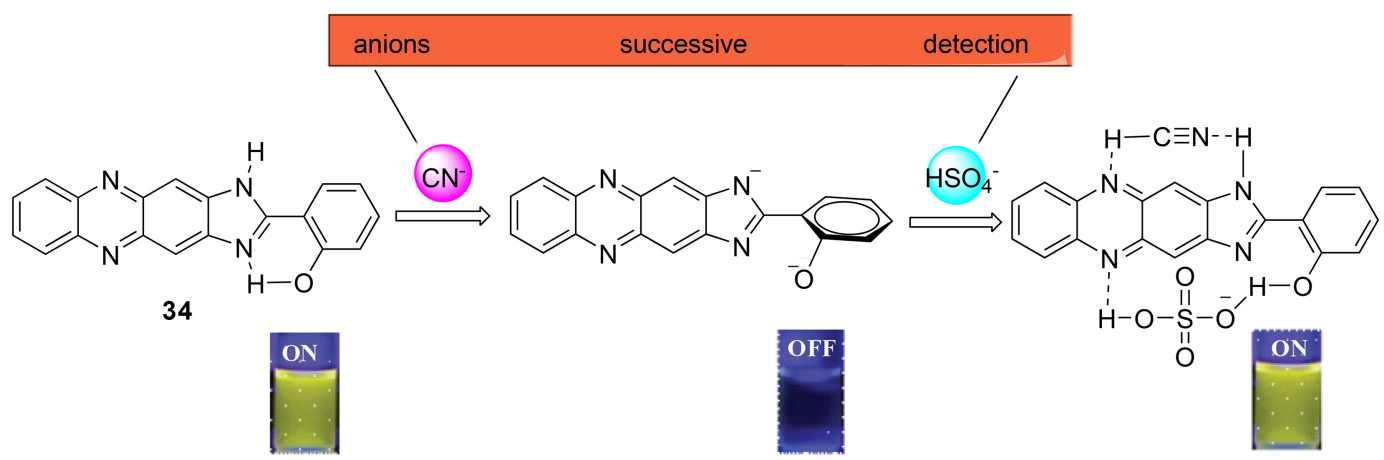

图 24 化合物 34 识别 $\mathrm{CN}^{-}$的机理

Figure 24 Recognition mechanism of compound 34

式下降. 这种 $\mathrm{CN}^{-}$的光学信号改变是因为 $\mathrm{CN}^{-}$与两个二 氧乙烯基发生迈克尔加成反应, 把这些电子受体转化为 阴离子电子给体, 从而破坏了共轭, 最终影响了化学传 感器的 ICT 效应和荧光. 结果表明, 该传感器的灵敏度 高, 响应时间小于 $50 \mathrm{~s}$, 对 $\mathrm{CN}^{-}$的选择性较高, 最低检 测限为 $3.2 \times 10^{-9} \mathrm{~mol} \cdot \mathrm{L}^{-1}$.

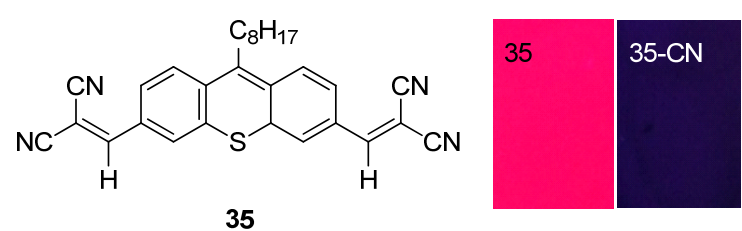

2017 年 Wang 等 ${ }^{[79]}$ 合成了一个三苯胺修饰的氟硼二 吡咯 36, 该分子在一个三苯胺中心体上连有三个 2-甲 酰基氟嗍二吡咯基团, 在其中包含有电子给体和受体. 因为分子内电子给体和受体被桥连的苯基阻碍, 所以传 感器中不存在扭曲的分子内电荷转移(TICT)效应. 然 而, 它的发射峰可以通过增加溶剂黏度和降低溶液温度 来增强, 这表明聚集诱导发射(AIE)效应是由抑制分子 内发光体引起的. 作者发现, 36 可以作为 $\mathrm{F}^{-}$和 $\mathrm{CN}^{-}$的比 色和荧光化学传感器, 不受任何其它阴离子的干扰. 当 在传感器 36 的 $\mathrm{THF} / \mathrm{H}_{2} \mathrm{O}(V: V=98: 2)$ 溶液中分别加 入 $\mathrm{F}^{-}$和 $\mathrm{CN}^{-}$后, 能够用肉眼观察到溶液快速地由黄色 变成肉色和无色. ${ }^{1} \mathrm{H} N \mathrm{NMR}$ 证明 $\mathrm{CN}^{-}$和 $\mathrm{F}^{-}$优先进攻氟硼 二吡咯的硓中心，而不是甲酰基部分.

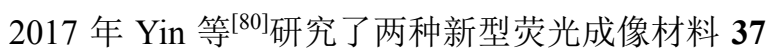
和 38, 并以标准的分析工具和光谱技术对它们进行了 充分地分析. 在多种阴离子存在时, 传感器 $\mathbf{3 7}$ 和 $\mathbf{3 8}$ 在 HEPES/DMSO $(V: V=1: 1, \mathrm{pH}=7.4)$ 中都能够对 $\mathrm{CN}^{-}$ 展现出高选择的响应. 之后用 ${ }^{1} \mathrm{H} N \mathrm{NR}$ 和 MS 证明了它 们的识别机理为 $\mathrm{CN}^{-}$对分子上的沿哚核进攻, 使溶液 苂光增强. ${ }^{1} \mathrm{H}$ NMR 和 $\mathrm{MS}$ 表明，在离子化过程中, $\mathrm{CN}^{-}$ 与吲哚的亲核性加成是可逆的. 对于传感器的实际应 用, 37 可以应用于生物荧光显微镜成像技术.

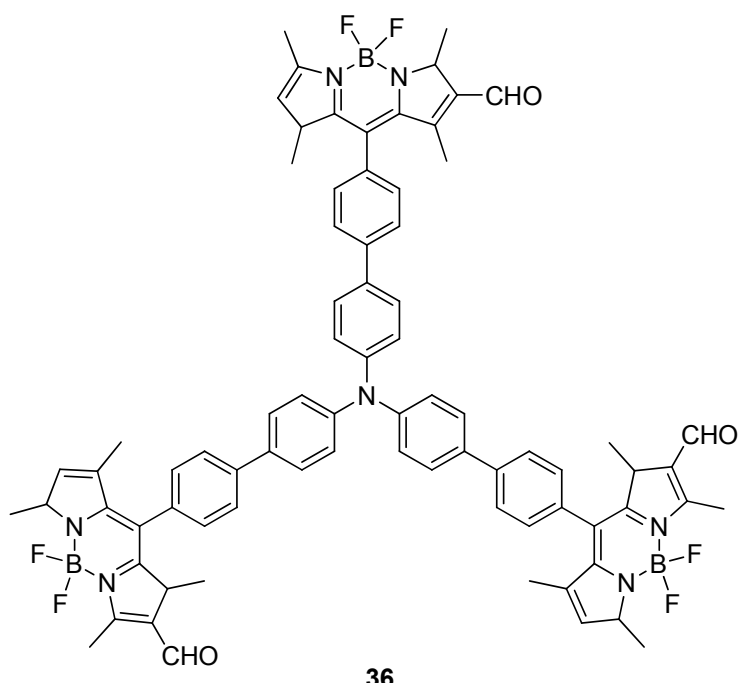

36<smiles>Cn1c(/C=C/c2ccc(N(c3ccccc3)c3ccc(/C=C/C4=[N+](C)c5ccccc5C4(C)C)cc3)cc2)[n+](C)c2ccccc21</smiles>

37

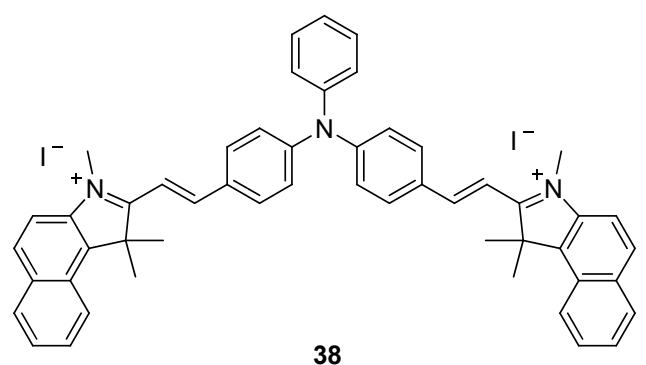

2017 年我们课题组 ${ }^{[81]}$ 设计合成了一个基于亲核加 成反应过程识别 $\mathrm{CN}^{-}$的化学传感器 39. 该传感器能够 在 $\mathrm{DMSO} / \mathrm{H}_{2} \mathrm{O}(V: V=8: 2, \mathrm{HEPES}, \mathrm{pH}=7.20)$ 中单一 选择性的识别 $\mathrm{CN}^{-}$, 并且该过程能够从荧光明显增强表 现出来, 这一过程不会受到其他共存阴离子的干扰. 经 
过研究我们发现传感器 39 对 $\mathrm{CN}^{-}$具有很低的检测限. 此外, 通过应用性实验, 我们得出传感器 39 的溶液能够 有效地检测樱桃核中的 $\mathrm{CN}^{-}$, 基于传感器 39 的检测试 纸能够很好的检测水溶液中的 $\mathrm{CN}^{-}$.<smiles>O=C(Nc1cccc2ccccc12)c1cc2ccccc2oc1=O</smiles>

39

\section{3 纯水相中的氭根离子识别进展}

2011 年 Shiraishi 等 $^{[82]}$ 合成了一种简单的共聚物 40, 由 $N$-异丙基丙烯酰胺和共轭的香豆素螺吡喃单元组成. 这种共聚物可以在室温下对水中的 $\mathrm{CN}^{-}$进行选择性的 苂光检测。这种共聚物本身几乎没有苂光, 但当加入 $\mathrm{CN}^{-}$后, 在紫外光照射下显示出强烈的蓝色苂光. 苂光 增强是由于 $\mathrm{CN}^{-}$与螺吡喃和 $N$-异丙基丙烯酰胺桥连的 碳发生亲核加成反应, 导致 $\pi$-电子在香豆素环上定域 化. 这种共聚物能够精确地测定低浓度的 $\mathrm{CN}^{-}(0.5$ $\left.\mu \mathrm{mol} \cdot \mathrm{L}^{-1}\right)$. 因为加热引起共聚物的聚合, 共聚物可以在 高温下 $\left(>40{ }^{\circ} \mathrm{C}\right)$ 通过简单的离心方法从水中回收. 此 外, 共聚物通过简单的酸处理能重新生成, 结果显示回 收后的共聚物被成功地用于进一步的 $\mathrm{CN}^{-}$传感, 而不会 降低灵敏度.

2013 年我们课题组 ${ }^{[83]}$ 介绍了一种具有高度选择性
的化学传感器 41, 用酰肼部分作为结合位点和芸环部 分作为菼光信号报告基团，可以在水中瞬间选择性和高 灵敏度地检测 $\mathrm{CN}^{-}$. 通过 $\mathrm{CN}^{-}$对羰基上的碳发生亲核进 攻来检测 $\mathrm{CN}^{-}$，可以通过 ${ }^{1} \mathrm{H} \mathrm{NMR} 、{ }^{13} \mathrm{C} \mathrm{NMR、ESI-MS}$ 和 DFT 计算得到证实. 将 $\mathrm{CN}^{-}$加入到传感器 41 中, 溶 液颜色从无色变到黄色，并且有蓝色的苂光产生，这种 传感过程没有被其它共存的阴离子干扰. 根据荧光滴定 计算出该传感器的最低检测限为 $2.0 \times 10^{-9} \mathrm{~mol} \cdot \mathrm{L}^{-1}$. 基 于传感器 41 的试纸被制作出来, 可以作为一种方便、有 效的 $\mathrm{CN}^{-}$检测工具.

2014 年 Xue 等 ${ }^{[84]}$ 合成了一种新型多功能苂光化学 传感器 42, 该传感器是基于柱 5 芳烃(WP5)和 10-碘代叫 啶 $(G)$ 在水之间的相互作用而建立的. 这种没有苂光的 复合物能够被用作荧光打开的化学传感器, 用来检测水 中的百草枯，因为 WP5-百草枯的结合能力比 WP5-G 的 结合能力强很多. 这种识别不仅体现在两种客体与 WP5 的竞争包接能力, 同时也有 $\mathrm{pH}$ 响应. 通过改变溶 液的 $\mathrm{pH}$ 值, 可逆地控制组装和拆卸过程. 与此同时, $\mathrm{CN}^{-}$可以与 $\mathrm{G}$ 中 9 号位发生亲核加成反应，作为一种测 定水中的 $\mathrm{CN}^{-}$苂光传感器.

2014 年 Hossain 等 ${ }^{[85}$ 报道了一个独特的传感器 43(图 26), 它能够在水中检测含量为 $0.020 \mu \mathrm{mol} / \mathrm{L}$ 的 $\mathrm{CN}^{-}$, 这比环境保护局(EPA)规定的饮用水中的 $\mathrm{CN}^{-}$标 准 $(0.20 \mu \mathrm{mol} / \mathrm{L})$ 要低得多. 这个现成的传感器能够成功<smiles>Cc1cc(=O)oc2c3c(ccc12)OC1(C=C3)N(C)c2ccccc2C1(C)C</smiles>

40

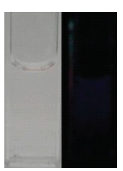

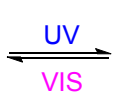

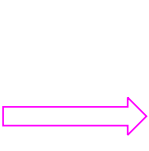<smiles>C=CC1(C)N(C)c2ccccc2C1(C)C</smiles>

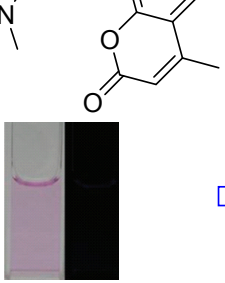

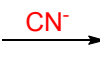

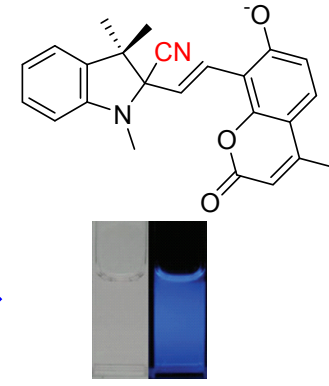

图 25 化合物 $\mathbf{4 0}$ 识别 $\mathrm{CN}^{-}$的机理

Figure 25 Recognition mechanism of compound $\mathbf{4 0}$<smiles>CCCCN1C2C=CC=CN2C1CCC(=O)N/N=C\c1c(O)ccc2ccccc12</smiles>

41

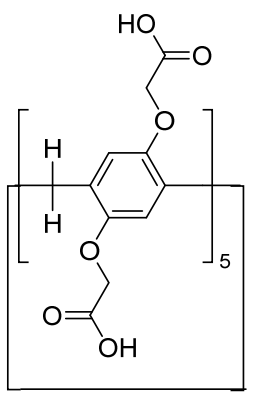

42
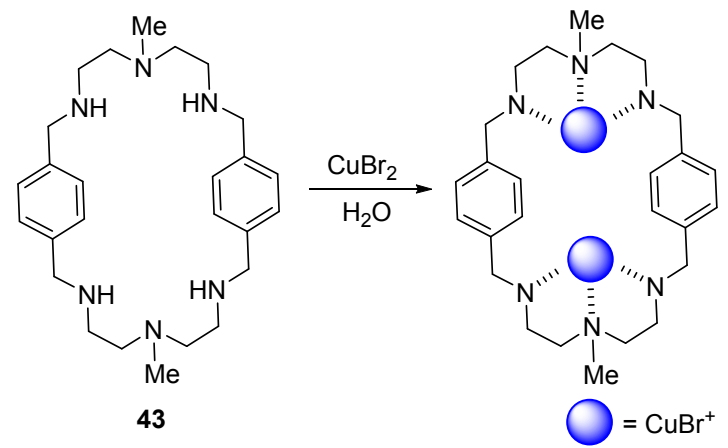

图 26 化合物 $\mathbf{4 3}$ 的合成过程

Figure 26 Synthetic progress of compound $\mathbf{4 3}$ 
地检测两种市售染料中的 $\mathrm{CN}^{-}$, 而没有受到其它 10 种 阴离子的干扰. 离散傅里叶变换(DFT)的计算结果进一 步表明, $\mathrm{CN}^{-}$通过强大的静电相互作用, 在受体分子的 两个铜离子之间架起了桥梁. 这一策略提供了对环境和 生物相关的选择性光学传感器的合理设计.

2015 年 Lee 等 $^{[86]}$ 合成了一个基于肽链铜配体的化 学传感器 44, 用于在纯水介质中比色-荧光检测 $\mathrm{CN}^{-}$(图 27). 肽链中的 7-硝基-2,1,3-苯并呋喃与 $\mathrm{Cu}^{2+}$ 结合, 导致 溶液颜色从黄色到橙色的变化, 并且减少了苂光的释 放. 整个铜配合物能够灵敏且有选择性地在 $100 \%$ 的水 溶液中检测到浓度较低的 $\mathrm{CN}^{-}$. 在 $100 \%$ 的水溶液中加 入 $\mathrm{CN}^{-}, \mathrm{CN}^{-}$立即将 $\mathrm{Cu}^{2+}$ 从传感器配合物上络合下来, 从而使溶液的颜色从橙色变为黄色, 并产生了一种 “打 开”的荧光反应. 以肽链为基础的配合物是一种潜在的、 实用的方法, 可以在 $100 \%$ 溶液中检测亚微米浓度的 $\mathrm{CN}^{-}$.

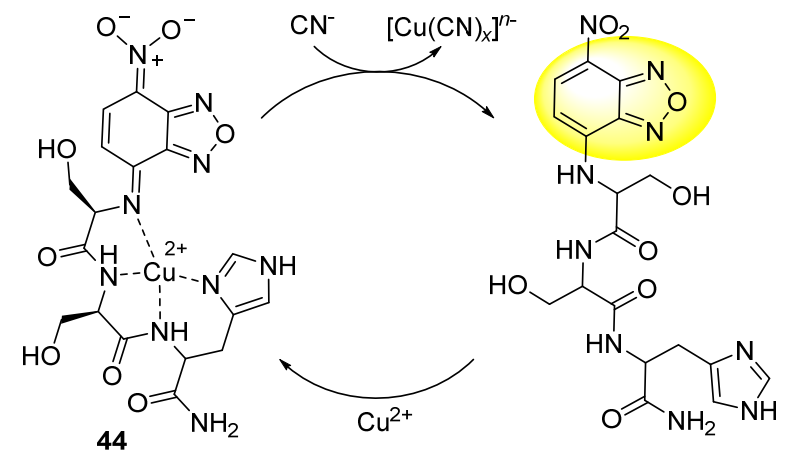

图 27 化合物 44 识别 $\mathrm{CN}^{-}$的机理

Figure 27 Recognition mechanism of compound $\mathbf{4 4}$

2016 年 Yang 等 ${ }^{[87]}$ 合成了化合物 45, 将其制备成铜 纳米粒子(CuNPs), 研究其依赖 DNA 序列的 DNA-CuNP 作为苂光团的光相互作用. 这是第一次发现 DNACuNP 在苂光传感器的构筑中作为理想的苂光猝灭剂, 它可以根据一个类似于埃尔斯纳的反应被 $\mathrm{CN}^{-}$打开荧 光, 并且信号的开关依赖于聚合 DNA 序列的变化. 由 于纳米粒子尺寸很小, 并且与 $\mathrm{CN}^{-}$的化学反应活性很 高, 所以苂光很强, 类似于一盏打开的灯, 这对于精确 监控短半衰期的 $\mathrm{CN}^{-}$是非常重要的. 由于 $\mathrm{CN}^{-}$与 DNA-CuNP 之间独特的类似于埃尔斯纳的反应, 高选 择性的纳米离子在实际的水和食物样本中得到了实际 应用。

2016 年 Bhowmick 等 ${ }^{[88]}$ 首次报道了以 $\mathrm{Co}^{\mathrm{II}}$-二重三 联吡啶配合物 46 , 它在包括水在内的极性溶剂中能够 对 $\mathrm{CN}^{-}$“裸眼” 比色检测, 生成了相应的 $\mathrm{Co}^{\mathrm{III}}$-三联吡啶 配合物. 新的 $\mathrm{Co}^{\mathrm{III}}$ 三联吡啶配合物 $\mathrm{Co}^{\mathrm{III}}$ (4-吡啶 $)(\mathrm{CN})_{3}$ 的结构特征通过单晶 XRD 衍射能够被证明. 作者采用 紫外-可见分光光度法对 $\mathrm{CN}^{-}$的传感性能进行研究, 并

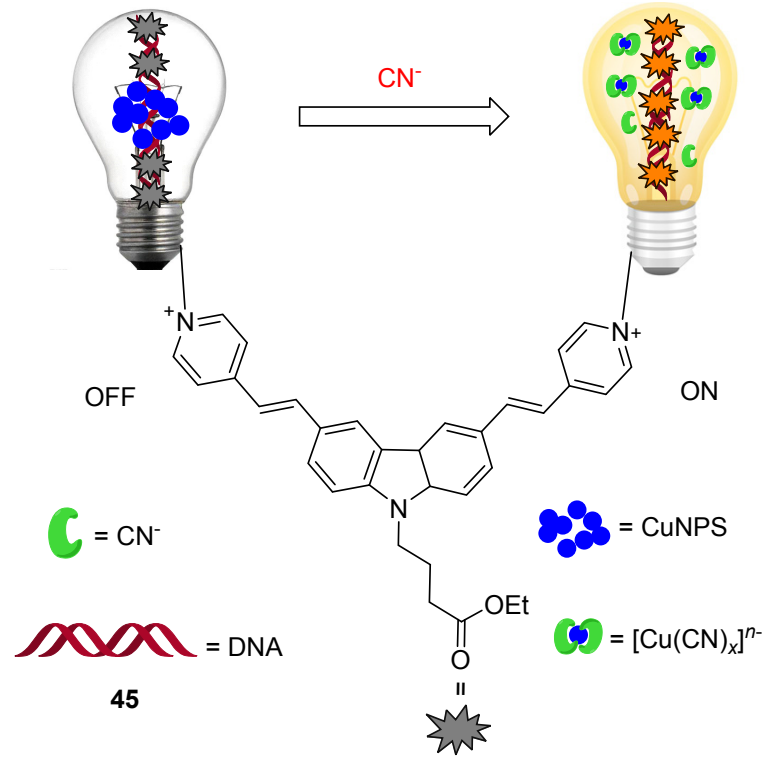

图 28 DNA-CuNP 45 识别 $\mathrm{CN}^{-}$的机理

Figure 28 Recognition mechanism of DNA-CuNP 45

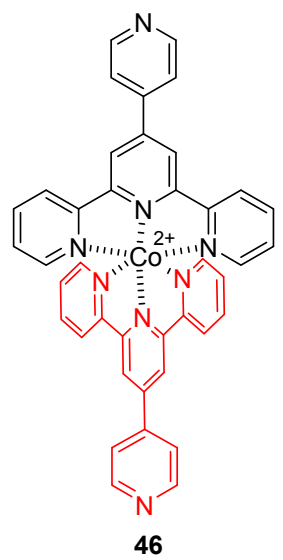

通过添加其它阴离子, $\mathrm{Co}^{\mathrm{II}}$-二重三联吡啶配合物对 $\mathrm{CN}^{-}$ 的选择性进行了研究.

2016 年我们课题组 ${ }^{[89}$ 设计并合成了一种基于二羟 基吩嗪的 $\mathrm{CN}^{-}$菼光化学传感器 47(图 29). 该传感器 47 在纯水中具有较高的灵敏度和选择性. $\mathrm{CN}^{-}$响应机理为 传感器的氢键和脱质子过程, 从而引起了显著的荧光增 强过程. 传感器对 $\mathrm{CN}^{-}$的最低检测限为 $5.65 \times 10^{-7}$ $\mathrm{mol} \cdot \mathrm{L}^{-1}$, 而其它的阴离子对这个传感性质几乎没有影 响. 此外, 基于传感器的试纸也被制造出来, 在水中也 有良好的选择性. 值得注意的是, 这个传感器被成功地 用于检测食物样本中的 $\mathrm{CN}^{-}$, 这证明了这是一个非常简 单的工具, 用于在农业样本中对 $\mathrm{CN}^{-}$进行检测.

2016 年 Zeng 等 ${ }^{[90]}$ 合成了 $\mathrm{Ag} @ \mathrm{Au}$ 核壳纳米粒子 (48), 并将其作为对水溶液中检测 $\mathrm{CN}^{-}$的比色传感器, $\mathrm{Ag} @ \mathrm{Au}$ 核壳纳米粒子加入 $\mathrm{CN}^{-}$前后的性质通过紫外吸 收光谱、透射电子显微镜、电喷射电离飞行时间质谱进 


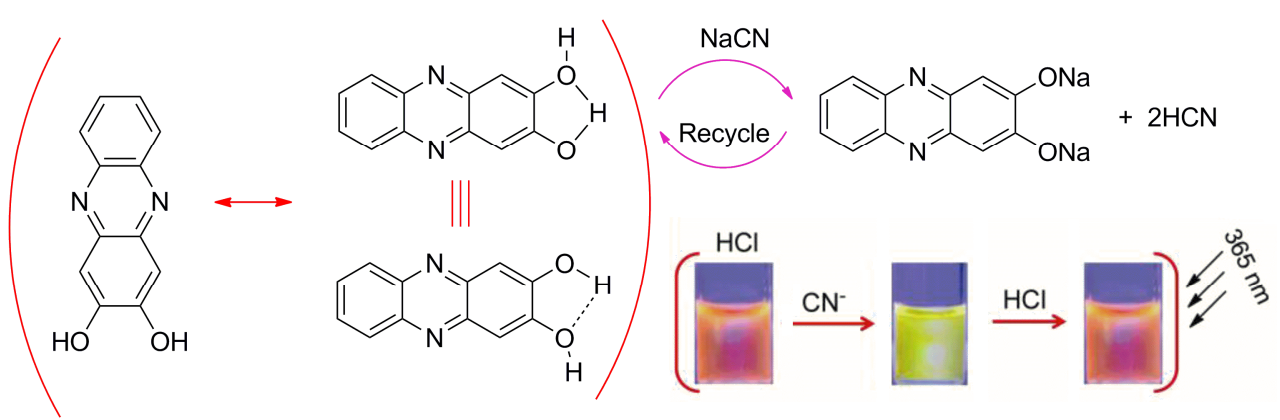

图 29 化合物 47 识别 $\mathrm{CN}^{-}$的机理

Figure 29 Recognition mechanism of compound 47

行验证. 这种传感的机理是基于 $\mathrm{CN}^{-}$能够连续腐蚀双金 属纳米粒子的金壳和银核, 溶液的颜色从紫色到橙色, 黄色, 最后是无色(图 30). 通过滴定实验可以得出在 $520 \mathrm{~nm}$ 处的吸光度变化与溶液中 $\mathrm{CN}^{-}$的含量成线性关 系, 相关系数达到 0.995 . 最低检测限是 $0.16 \mu \mathrm{mol} \cdot \mathrm{L}^{-1}$, 这在纳米粒子比色法中是最低的检测限. 比色传感实验 证明, 在其它 16 个阴离子存在时, $\mathrm{Ag} @ \mathrm{Au}$ 核壳纳米粒 子对 $\mathrm{CN}^{-}$展现出非常好的选择性. 该方法可用于饮用水 中 $\mathrm{CN}^{-}$的分析, 回收率为 $90 \% \sim 116.4 \%$, 相对标准偏差 低于 $6.7 \%$.
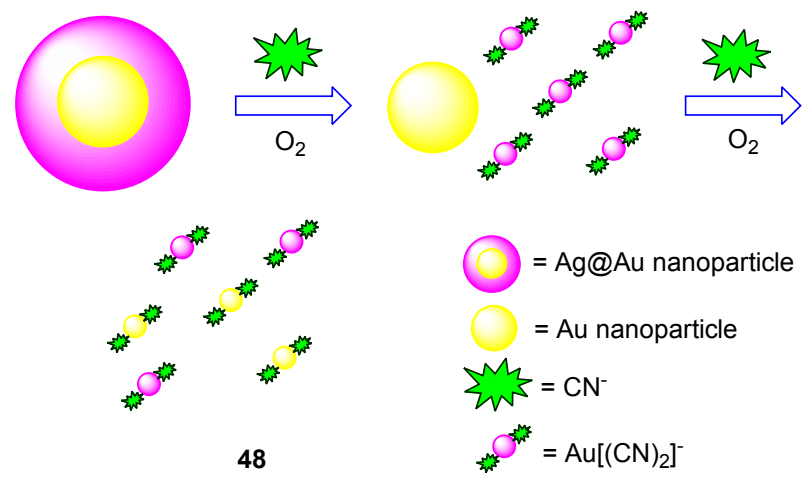

48

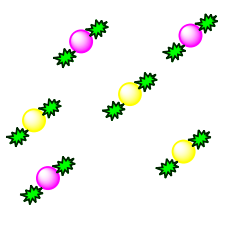

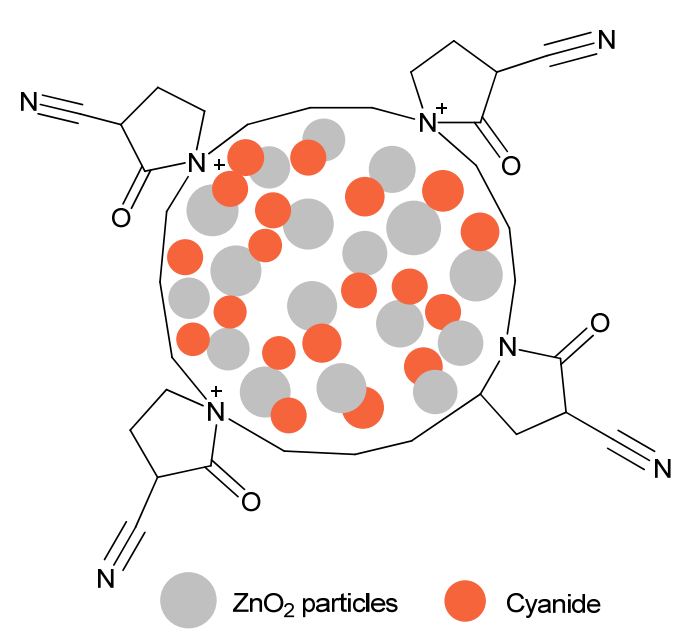

图 31 纳米粒子 49 识别 $\mathrm{CN}^{-}$的机理

Figure 31 Recognition mechanism of nanopartical 49

2017 年我们课题组 ${ }^{[92]}$ 报道了一种新颖高效的荧光 检测水中离子的方法, 这个方法由基于柱 5 芳烃上的超 分子传感器 50 完成的. 这种新颖的方法如下所示: 首 先, 水溶性阳离子柱 5 芳烃(P5)和功能化的菜酰亚胺衍 生物(N2)在水中自组装, 形成超分子传感器(P5N2), 然 后, 在超分子传感器 $\mathrm{P} 5 \mathrm{~N} 2$ 上引入了竞争配位, 加入了 $\mathrm{Al}^{3+}$, 形成了新的超分子传感器( $\left.\mathrm{P} 5 \mathrm{~N} 2 \mathrm{Al}\right)$, 超分子传感 器 P5N2 可以识别水中的 $\mathrm{Al}^{3+}$, 而超分子传感器 P5N2Al 可以在水中高选择性和灵敏度的识别水中的 $\mathrm{CN}^{-}$. 因 此, 对于传感器的设计来说这是一种新颖而又简单的方 法可以有效地识别水中的阴阳离子.

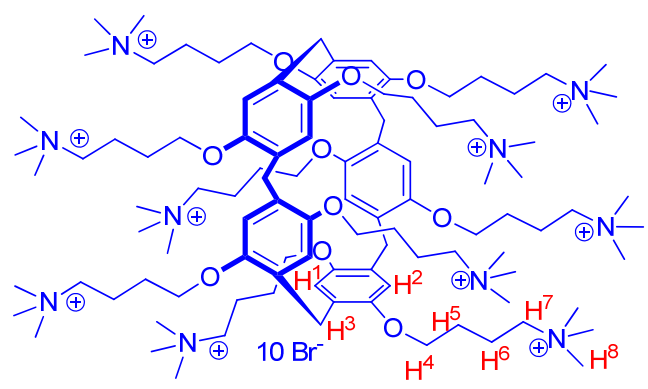

50 到, 数据不仅遵循了等温线, 也遵循了二阶动力学. 
2017 年 Momeni 等 ${ }^{[93]}$ 报道了一种简单而绿色的方 法, 用于测定水中的 $\mathrm{CN}^{-}$, 它是基于铜纳米粒子 $\mathbf{5 1}$ 在水 溶液中充当苂光传感器的(图 32). 本研究中, 苂光纳米 粒子在抗坏血酸当保护剂的情况下被合成出来. 这种方 法的制备非常简单, 成本低, 产率高, 可重复使用. 准 备好的纳米粒子的平均直径为 $10 \mathrm{~nm}$, 在 $440 \mathrm{~nm}$ 处出现 了发射峰, 并且溶液发出蓝色苂光. 然而, 在将 $\mathrm{CN}^{-}$加 入到纳米粒子传感体系的过程中, 由于 $\mathrm{CN}^{-}$和铜之间的 强相互作用, 它的菼光被明显地猝灭了. 在最佳的条件 下, 纳米粒子的荧光最低检测限 $0.37 \mu \mathrm{mol} \cdot \mathrm{L}^{-1}$. 该传感 器具有较高的选择性和简单的操作, 可以在水样中苂光 传感 $\mathrm{CN}^{-}$.

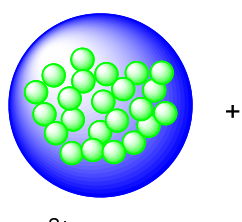

$\mathrm{Cu}^{2+}$ nanoparticle

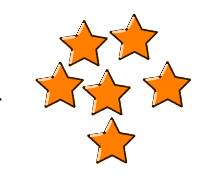

$\mathrm{CN}^{-}$

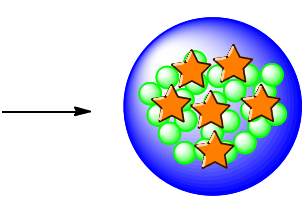

图 32 纳米粒子 51 识别 $\mathrm{CN}^{-}$的机理

Figure 32 Recognition mechanism of nanopartical 51

\section{4 固相中的氧根离子识别进展}

2012 年 Zelder 等 ${ }^{[94]}$ 描述了一种用固相空间分离提 取作为一种快速、有效和经济的方法来光学检测复杂样 品中的 $\mathrm{CN}^{-}$. 该固相体系 52 对 $\mathrm{CN}^{-}$的光学检测比在同 条件下使用的同类型的化学传感器要灵敏 7 倍. 本文介 绍了该方法检测如下几种样品: (1)有色植物样品中的内 源性 $\mathrm{CN}^{-}$和(2)烟草烟雾中的 $\mathrm{HCN}$. 在一个简单的样本 中, 对多个阴离子的光学响应已经被证明, 52 可以用于 检测 $\mathrm{CN}^{-}$和 $\mathrm{SCN}^{-}$. 固化的水溶氰酸酯和固化的维生素 B12 被用作化学传感器, $\mathrm{CN}^{-}$的定性检测是通过生成相 应的二氰基配合物, 使溶液的颜色由黄色变成紫色. 烷 基修饰的二氧化硅颗粒被用于在固相表面(检测区)固定 传感分子, 并且可以去除彩色的疏水干扰物(萃取区).

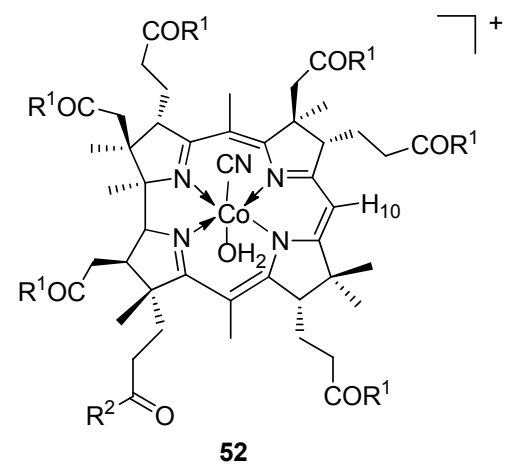

2014 年 $\mathrm{Lu}$ 等 ${ }^{[95]}$ 成功地合成出一种能够快速地、灵 敏地、选择性地检测 $\mathrm{CN}^{-}$的发磷光的高分子 $\mathrm{Au}(\mathrm{I})$ 族
53(图 33). 通过 X 射线吸收边缘结构(XANES)分析和扩 展 $X$ 射线吸收精细结构(EXAFS)分析, 得出分子 $\mathrm{Au}(\mathrm{I})$ 族对 $\mathrm{CN}^{-}$表现出突出的传感性能是合理的. 与其它 $\mathrm{CN}^{-}$ 传感器相比, $\mathrm{CN}^{-}$与分子 $\mathrm{Au}(\mathrm{I})$ 簇的反应机理表现出了几 个关键的传感器特点. 重要的是, 通过对固态的分子 $\mathrm{Au}(\mathrm{I})$ 簇的磷光特性的研究，作者首次展示了一个基于 高分子 $\mathrm{Au}(\mathrm{I})$ 族的宏观多孔传感膜, 用于在复杂的样品 中检测 $\mathrm{CN}^{-}$, 包括红酒、咖啡、果汁和土壤. 制备的传 感膜继承了分子 $\mathrm{Au}(\mathrm{I})$ 族的传感能力, 并提供了一种高 度灵敏的工具，可以实时监测木薯中的 $\mathrm{CN}^{-}$.
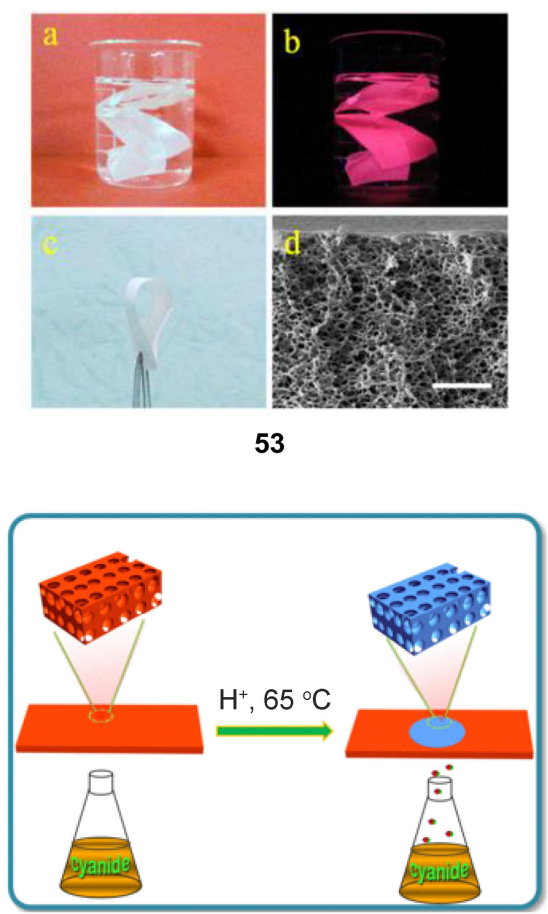

图 33 高分子簇 $\mathbf{5 3}$ 识别 $\mathrm{CN}^{-}$的机理

Figure 33 Recognition mechanism of polymer clusters $\mathbf{5 3}$

2015 年我们课题组 ${ }^{[96]}$ 研究了一种新型的超分子金 属离子传感器阵列, 值得一提的是, 这个五元的传感器 阵列只需要一个合成的有机化合物 54. 凝胶因子在有 机凝胶的状态表现出很强的聚集态苂光增强(AIE)效应, 54 和阴离子的响应特性可以由不同的金属离子来调节. 这个传感器阵列实现选择性的响应阴离子是通过凝胶 用不同金属离子和阴离子的竞争配位. 这个传感器阵列 可以识别 $\mathrm{S}^{2-} 、 \mathrm{I}^{-} 、 \mathrm{CN}^{-} 、 \mathrm{SCN}^{-}$四种阴离子，具有较高 的选择性和灵敏度. 此外，基于 54 的金属有机凝胶膜不 仅可以作为方便的可逆的阴离子 $\left(\mathrm{CN}^{-} 、 \mathrm{SCN}^{-} 、 \mathrm{~S}^{2-} 、 \mathrm{I}^{-}\right)$ 检测工具, 还可以作为可擦除的安全显示材料. “竞争 协调控制 AIE 模式” 的概念提供了一种简单的方法, 可 以合成基于金属的具有反应性的荧光材料，如传感器阵 列和其它超分子功能材料. 


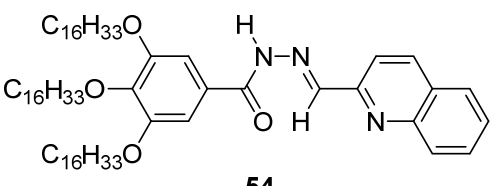

54

2016 年 Aslan 等 ${ }^{[97]}$ 报道了基于近红外 786 高氯酸盐 (IR-786)的传感器 55 作为在纯有机相和无溶剂的固体表 面高选择性地检测 $\mathrm{CN}^{-}$. 在纯 $\mathrm{MeCN}$ 中, IR-786 对两个 阴离子 $\left(\mathrm{CN}^{-}\right.$和 $\left.\mathrm{OH}^{-}\right)$都具有选择性, 在 IR-786 的 $\mathrm{MeCN}$ 溶液中, 由于对 $\mathrm{CN}^{-}$的亲核加成反应, IR-786 的苂光黄 到暗绿色的显著的颜色变化, 紫外吸收光谱从 $775 \mathrm{~nm}$ 蓝移至 $430 \mathrm{~nm}$ 的变化, 也证明了 IR-786-(CN)的形成, 同时 IR-786-(CN) 在 $\mathrm{MeCN}$ 中明显的绿色苂光, 也证明 了在 $\mathrm{MeCN}$ 中对 $\mathrm{CN}^{-}$的选择性. 同时, IR-786 作为一种 无溶剂固体状态传感器在环境中潜在应用的研究, 也证 明了传感器 55 可用于对环境中 $\mathrm{CN}^{-}$高选择性的传感. 在无溶剂固体状态表面, IR-786 可以灵敏地检测到水样 本中到 $50 \sim 300 \mu \mathrm{mol} \cdot \mathrm{L}^{-1}$ 的 $\mathrm{CN}^{-}$, 氢氧根的干扰是很小 的.

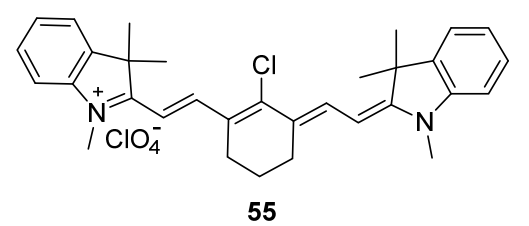

2017 年 Y $11 \mathrm{~d} 1 \mathrm{z}$ 等 ${ }^{[98]}$ 演示了一个基于传感分子 $\mathbf{5 6}$ 的 一次性使用试纸平台, 以苂光增强的方式检测 $\mathrm{CN}^{-}$. 报 道的这个方法采用定制的图像处理算法, 使描述的这个 简单的定量检测 $\mathrm{CN}^{-}$的方法标准化, 通过识别试纸的颜 色, 其对 $\mathrm{CN}^{-}$的最低检测限低至 $10^{-12} \mathrm{~mol} \cdot \mathrm{L}^{-1}$. 这种普 通的算法适用于配备有摄像头的普通智能手机, 并将设 备中的数据转换成定量 $\mathrm{CN}^{-}$浓度.

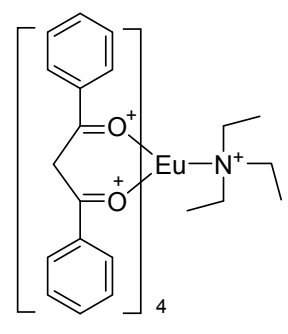

56

2017 年 Son 等 ${ }^{[99]}$ 开发和合成了一种新的比色和苂 光化学传感器 $\mathbf{5 7}$, 它在 $80 \%$ 的含水介质中比色和荧光 检测 $\mathrm{CN}^{-}$. 可以用肉眼观察到, 当 $\mathrm{CN}^{-}$加入后, 受体的 紫外吸收(红移)和荧光发射(增强)都发生了变化. 作者 通过 ${ }^{1} \mathrm{H}$ NMR 和密度泛函理论说明传感器分子与 $\mathrm{CN}^{-}$ 之间发生了去质子化. 该受体允许高选择性检测低浓度 的 $\mathrm{CN}^{-}$, 这一浓度低于世界卫生组织规定的水平. 因此,
这种识别行为使这种受体成为一种潜在的传感工具, 在 实际应用中检测 $\mathrm{CN}^{-}$. 此外, 这种传感器受体的固体对 $\mathrm{CN}^{-}$的检测也很灵敏.

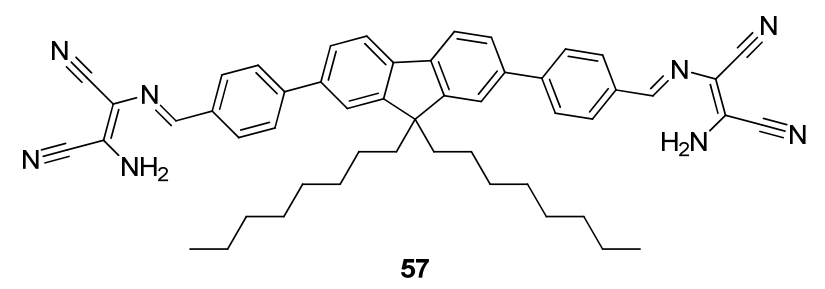

2017 年 Singh 等 ${ }^{[100]}$ 根据 $\mathrm{CN}^{-}$特殊的亲和性, 设计 用 2-甲氧基-1-荎甲醛合成了两个双重激活的迈克尔加 成化学计量苂光传感器 $\mathbf{5 8}, \mathbf{5 9}$. 当 $\mathrm{CN}^{-}$与缺电子的桥连 的烯烃加成时，分子中的电子给体和受体被阻断，从而 阻断了分子内的电荷转移 (ICT)过程. 通过紫外吸收和 荧光发射光谱的变化, 观察到加成产物的紫外光谱蓝移 并且苂光增强. 红外光谱、核磁共振、质谱和密度函数 理论(DFT)进一步支持了传感器和 $\mathrm{CN}^{-}$之间的相互作用 机理. 同时, 传感器 $\mathbf{5 8}$ 在固体状态下同样在可见光下对 $\mathrm{CN}^{-}$展现出良好的响应性.

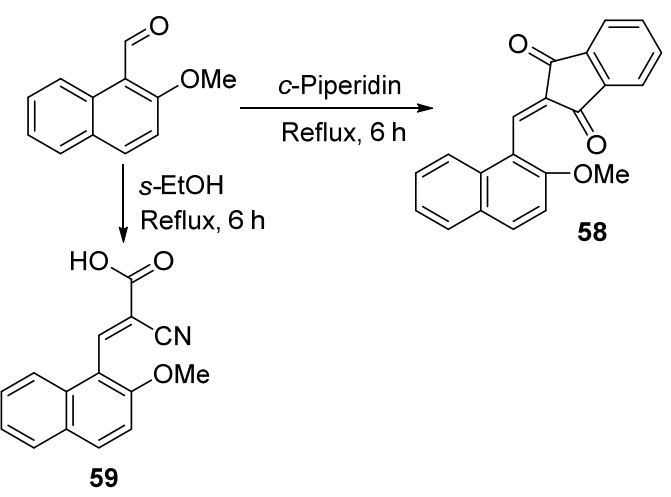

图 34 化合物 $\mathbf{5 8}$ 和 $\mathbf{5 9}$ 的合成过程

Figure 34 Synthetic progress of compounds $\mathbf{5 8}$ and $\mathbf{5 9}$

\section{3 结论与展望}

本文分别从纯有机相中的氧根离子识别、含水介质 中的氰根离子识别、纯水相中的氰根离子识别和固相中 的氰根离子识别四个方面综述了 2010 年以来关于氰根 离子识别的相关文献. 通过对这些传感器的合成方法, 检测手段和检测机理的研究, 能够总结出不同介质中氧 根传感器的一般规律, 为今后氧根传感器的发展和研究 提供一定的理论参考价值. 总而言之, 由于化学传感器 方便、快捷和成本低等优点, 利用人工合成的传感材料 检测不同介质中的 $\mathrm{CN}^{-}$迅速得到了广大科研工作者的 关注. 因此, 超分子化学领域中有大量涉及到小分子和 聚合物的 $\mathrm{CN}^{-}$传感器, 以及对新型纳米材料的合成和物 
理化学特性的研究. 将这些不同领域的 $\mathrm{CN}^{-}$传感器研究 整合在一起, 代表了功能化传感材料领域的最新的和其 重要的发展. 在环境污染的话题进入白热化的时期, 该 综述将为以后的 $\mathrm{CN}^{-}$传感材料设计提供更多的帮助, 具 有潜在的参考价值.

\section{References}

[1] Anzenbacher, J. P.; Lubal, P.; Bucek, P.; Palacios, M. A.; Kozelkova, M. E. Chem. Soc. Rev. 2010, 39, 3954.

[2] Gale, P. A.; Garcia-Garrido, S. E.; Garric, J. Chem. Soc. Rev. 2008, $37,151$.

[3] Lemos, S. G.; Nogueira, A. R. A.; Torre-Neto, A. Parra A.; Alonso, J. J. Agric. Food. Chem. 2007, 55, 4658.

[4] Wang, Q.; Xie, Y.; Ding, Y. Li, X.; Zhu, W. Chem. Commun. 2010, $46,3669$.

[5] Lin, Q.; Zhu, X.; Chen, P.; Fu, Y. P.; Zhang, Y. M.; Wei, T. B. Acta Chim. Sinica 2013, 71, 1516 (in Chinese).

(林奇, 朱金金, 陈佩, 符永鹏, 张有明, 魏太保, 化学学报, 2013, $71,1516$.

[6] Qu, W. J.; Li, W. T.; Zhang, H. L.; Zhang, Y. M.; Lin, Q.; Yao, H.; Wei, T. B. Chin. J. Org. Chem. 2018, 38, 1792 (in Chinese). (曲文娟, 李文婷, 张海丽, 张有明, 林奇, 姚虹, 魏太保, 有机 化学, 2018, 38, 1792.)

[7] Li, W. T.; Qu, W. J.; Zhang, H. L.; Li, X.; Lin, Q.; Yao, H.; Zhang, Y. M.; Wei, T. B. Chin. J. Org. Chem. 2017, 37, 2619 (in Chinese). (李文婷, 曲文娟, 张海丽, 李翔, 林奇, 姚虹, 张有明, 魏太保, 有机化学, 2017, 37, 2619.)

[8] Xu, Z.; Chen, X.; Kim, H. N.; Yoon, J. Chem. Soc. Rev. 2010, 39, 127.

[9] Sen, B.; Mukherjee, M.; Pal, S.; Mandal, S. K.; Hundal, M. S.; Khuda-Bukhshb, A. R.; Chattopadhyay, P. RSC $A d v$. 2014, 4, 15356.

[10] Li, Q.; Guo, Y.; Shao, S. Analyst 2012, 137, 4497.

[11] Li, Q.; Yue, Y.; Guo, Y.; Shao, S. Sens. Actuators, B 2012, 173, 797.

[12] Vennesland, B.; Conn, E. E.; Knowles, C. J.; Westley, J.; Wissing, F. Cyanide in Biology, Academic Press, London, 1981.

[13] Way, J. L. Annu. Rev. Pharmacol. Toxicol. 1984, 24, 451

[14] Anderson, R.; Harland, W. Med., Sci. Law 1982, 22, 35.

[15] Becker, C. Vet. Hum. Toxicol. 1985, 27, 487.

[16] Zamecnik, J.; Tam, J. J. Anal. Toxicol. 1987, 11, 47.

[17] Levin, B. C.; Cabrera, F. M.; Landron, F.; Clark, H. M.; Rodriguez, J. R.; Gurman, J. L.; Droz, L.; Yoklavich, M. F.; Rechani, P. R; Kaye, S. J. Forensic Sci. 1990, 35, 151.

[18] Matsubara, K.; Akane, A.; Maseda, C.; Shiono, H. Forensic Sci. Int. 1990, 46, 203

[19] Mayes, R. W. J. Forensic Sci. 1991, 36, 179.

[20] Baird, C.; Cann, M. Macmillan 2005.

[21] Selkoe, D. J.; Schenk, D. Annu. Rev. Pharmacol. Toxicol. 2003, 43, 545.

[22] Young, C.; Tidwel, L. Cyanide: Social, Industrial and Economic Aspects: Minerals, Metals, and Materials Society, Anderson, C., Warrendale, PA, 2001.

[23] Keshava, K.; Torawaneb, P.; Kumawatd, M. K.; Tayadeb, K.; Sahooc, S. K.; Srivastavad, R.; Kuwarb, A. Biosens. Bioelectron. 2017, 92,95 .

[24] Noh, J. Y.; Hwang, I. H.; Kim, H.; Song, E. J.; Kim, K. B.; Kim, C. Bull. Korean Chem. Soc. 2013, 34, 1985.

[25] Park, G. J.; Hwang, I. H.; Song, E. J.; Kim, H.; Kim, C. Tetrahedron 2014, 70, 2822

[26] Tang, L.; Zhou, P.; Zhong, K.; Hou, S. Sens. Actuators, B. 2013, $182,439$.

[27] Chen, X.; Nam, S. W.; Kim, G. H.; Song, N.; Jeong, Y.; Shin, I.; Kim, S. K.; Kim, J.; Park, S.; Yoon, J. Chem. Commun. 2010, 46, 8953.

[28] Qu, Y.; Jin, B.; Liu, Y.; Wu, Y.; Yang, L.; Wu, J.; Hua, J. Tetrahe- dron Lett. 2013, 54, 4942.

[29] Goswami, S.; Manna, A.; Paul, S.; Das, A. K.; Aich, K.; Nandi, P. K. Chem. Commun. 2013, 49, 2912.

[30] Lee, S. A.; You, G. R.; Choi, Y. W.; Jo, H. Y.; Kim, A. R.; Noh, I.; Kim, S. J.; Kim, Y.; Kim, C. Dalton Trans. 2014, 43, 6650.

[31] Lee, S. A.; You, G. R.; Choi, Y. W.; Jo, H. Y.; Kim, A. R.; Noh, I.; Kim, S. J.; Kim, Y.; Kim, C. Dalton Trans. 2014, 43, 6650.

[32] Jones, D. A. Phytochemistry 1998, 47, 15.

[33] Greenfield, R. A.; Brown, B. R.; Hutchins, J. B.; Iandolo, J. J.; Jackson, R.; Slater, L. N.; Bronze, M. S. Am. J. Med. Sci. 2002, $323,326$.

[34] Guidelines for Drinking-Water Quality. World Health Organization, Geneva, 1996

[35] Sun, S. S.; Lees, A. J. Chem. Commun. 2000, 17, 1687.

[36] Miyaji, H.; Sessler, J. L. Angew. Chem. 2001, 113, 158.

[37] Kim, Y.; Zhao, Y.; Gabbaï, F. P. Angew. Chem., Int. Ed. 2009, 48, 4957.

[38] Anzenbacher, P.; Tyson, D. S.; Jursíkova, K.; Castellano, F. N. J. Am. Chem. Soc. 2002, 124, 6232.

[39] Shang, L.; Jin, L.; Dong, S. Chem. Commun. 2009, 21, 3077.

[40] Senapati, D.; Dasary, S. S.; Singh, A. K.; Senapati, T.; Yu, H.; Ray, P. C. Chem.-Eur. J. 2011, 17, 8445 .

[41] Gimeno, N.; Li, X.; Durrant, J. R.; Vilar, R. Chem.-Eur. J. 2008, 14, 3006.

[42] Xu, Z.; Pan, J.; Spring, D. R.; Cui, J.; Yoon, J. Tetrahedron 2010, $66,1678$.

[43] Cheng, X.; Tang, R.; Jia, H.; Feng, J.; Qin, J.; Li, Z. ACS Appl. Mater. Interfaces 2012, 4, 4387.

[44] Cho, D. G.; Sessler, J. L. Chem. Soc. Rev. 2009, 38, 1647.

[45] Afkhami, A.; Sarlak, N. Sens. Actuators, B 2007, 122, 437.

[46] Badugu, R.; Lakowicz, J. R.; Geddes, C. D. J. Am. Chem. Soc. 2005, 127, 3635 .

[47] Wu, Y.; Wang, J.; Zeng, F.; Huang, S.; Huang, J.; Xie, H.; Yu, C.; Wu, S. ACS Appl. Mater. Interfaces 2016, 8, 1511.

[48] Kumari, N.; Jha, S.; Bhattacharya, S. J. Org. Chem. 2011, 76, 8215.

[49] Zhou, X.; Lv, X.; Hao, J.; Liu, D.; Guo, W. Dyes Pigm. 2012, 95 , 168.

[50] Dong, M.; Peng, Y.; Dong, Y. M.; Tang, N.; Wang, Y. W. Org. Lett. 2012, 14, 130 .

[51] Khatua, S.; Samanta, D.; Bats, J. W.; Schmittel, M. Inorg. Chem. 2012, 51,7075.

[52] Fillaut, J. L.; Akdas-Kilig, H.; Dean, E.; Latouche, C.; Boucekkine, A. Inorg. Chem. 2013, 52, 4890.

[53] Kang, J.; Song, E. J.; Kim, H.; Kim, Y. H.; Kim, Y.; Kim, S. J.; C. Kim, Tetrahedron Lett. 2013, 54, 1015.

[54] Yang, L.; Li, X.; Yang, J.; Qu, Y.; Hua, J. ACS Appl. Mater. Interfaces 2013, 5, 1317.

[55] Yang, Y.; Yin, C.; Huo, F.; Chao, J.; Zhang, Y.; Cheng, F. Sens. Actuators, B 2014, 193, 220.

[56] Liu, Y. W.; Kao, M. X.; Wu, A. T. Sens. Actuators, B 2015, 208, 429.

[57] Xing, P.; Xu, Y.; Li, H.; Liu, S.; Lu, A.; Sun, S. Sci Rep. 2015, 5, 16528

[58] Bejoymohandas, K. S.; Kumar, A.; Sreenadh, S.; Varathan, E.; Varughese, S.; Subramanian, V.; Reddy, M. L. P. Inorg. Chem. 2016, 55,3448 .

[59] Volpi, G. J. Chem. Educ. 2016, 93, 891.

[60] Wu, H.; Chen, Y.; Rao, C.; Fan, D.; Wei, H.; Liu, C. Tetrahedron Lett. 2016, 57, 4969.

[61] Wang, L.; Zhu, L.; Li, L.; Cao, D. RSC Adv. 2016, 6, 55182.

[62] Huo, F.; Zhang, Y.; Yue, Y.; Chao, J.; Zhang, Y.; Yin, C. Dyes Pigm. 2017, 143, 270.

[63] Liu, J.; Liu, Y.; Liu, Q.; Li, C.; Sun, L.; Li, F. J. Am. Chem. Soc. 2011, 133, 15276.

[64] Lee, H.; Kim, H. J. Tetrahedron Lett. 2012, 53, 5455.

[65] Jo, J.; Olasz, A.; Chen, C. H.; Lee, D. J. Am. Chem. Soc. 2013, 135, 3620.

[66] Robbins, T. F.; Qian, H.; Su, X.; Hughes, R. P.; Aprahamian, I. Org. 
Lett. 2013, 15, 2386.

[67] Lin, W. C.; Fang, S. K.; Hu, J. W.; Tsai, H. Y.; Chen, K. Y. Anal. Chem. 2014, 86, 4648.

[68] Pramanik, S.; Bhalla, V.; Kumar, M. ACS Appl. Mater. Interfaces 2014, 6, 5930.

[69] Qu, W.; Gao, G.; Shi, B.; Zhang, P.; Wei, T.; Lin, Q.; Yao, H.; Zhang, Y. Supramol. Chem. 2014, 26, 403.

[70] Qu, W.; Gao, G.; Shi, B.; Zhang, P.; Wei, T.; Lin, Q.; Yao, H.; Zhang, Y. Supramol. Chem. 2014, 26, 403.

[71] Chen, K. Y.; Lin, W. C. Dyes Pigm. 2015, 123, 1.

[72] Qiao, L.; Cai, Y.; Yao, H.; Lin, Q.; Zhu, Y. R.; Li, H.; Zhang, Y. M.; Wei, T. B. Spectrochim. Acta., Part A 2015, 136, 1047.

[73] Chow, C. F.; Ho, P. Y.; Wong, W. L.; Gong, C. B. Chem.-Eur. J. 2015, 21, 12984.

[74] Cheng, X.; Li, H.; Zheng, F.; Lin, Q.; Zhang, Y.; Yao, H.; Wei, T. Dyes Pigm. 2016, 127, 59.

[75] Jeong, J. W.; Angupillai, S.; Kim, I. J.; Jeonga, J.; Kim, H. S.; So, H. S.; Son, Y. A. Sens. Actuators, B 2016, 237, 341.

[76] Singh, Y.; Ghosh, T. Talanta 2016, 148, 257.

[77] Wei, T. B.; Li, W. T.; Li, Q.; Qu, W. J.; Li, H.; Yan, G. T.; Lin, Q.; Yao, H.; Zhang, Y. M. RSC Adv. 2016, 6, 43832.

[78] El-Shishtawy, R. M.; Al-Zahrani, F. A. M.; Al-amshany, Z. M.; Asiri, A. M. Sens. Actuators, B 2017, 240, 288.

[79] Wang, L.; Li, L.; Cao, D. Sens. Actuators, $B$ 2017, 241, 1224

[80] Liu, T.; Huo, F.; Li, J.; Cheng, F.; Yin, C. Sens. Actuators, B 2017, $239,526$.

[81] Chen, J.; Li, W.; Li, Q.; Lin, Q.; Yao, H.; Zhang, Y.; Wei, T. Chin. J. Chem. 2017, 35, 1165.

[82] Shiraishi, Y.; Sumiya, S.; Manabe, K.; Hirai, T. ACS Appl. Mater. Interfaces 2011, 3, 4649.

[83] Lin, Q.; Liu, X.; Wei, T. B.; Zhang, Y. M. Chem. Asian J. 2013, 8, 3015 .
[84] Wang, P.; Yao, Y.; Xue, M. Chem. Commun. 2014, 50, 5064.

[85] Rhaman, M. M.; Alamgir, A.; Wong, B. M.; Powell, D. R.; Hossain, M. A. $R S C A d v$. 2014, 4, 54263.

[86] Jung, K.; Lee, H. Anal. Chem. 2015, 87, 9308.

[87] Qing, Z.; Hou, L.; Yang, L.; Zhu, L.; Yang, S.; Zheng, J.; Yang, R. Anal. Chem. 2016, 88, 9759.

[88] Bhowmick, I.; Boston, D. J.; Higgins, R. F.; Klug, C. M.; Shores, M. P.; Gupta, T. Sens. Actuators, B 2016, 235, 325.

[89] Wei, T. B.; Li, W. T.; Li, Q.; Su, J. X.; Qu, W. J.; Lin, Q.; Yao, H.; Zhang, Y. M. Tetrahedron Lett. 2016, 57, 2767.

[90] Li, Y.; Wang, Q.; Zhou, X.; Wen, C.; Yu, J.; Han, X.; Li, X.; Yan, Z.; Zeng, J. Sens. Actuators, B 2016, 228, 366.

[91] Uppa, S. H.; Tripathy, S.; Chawla, S.; Sharma, B.; Dalai, M. K.; Singh, S. P.; Singh, S.; Singh, N. J. Environ. Sci. 2017, 55, 76.

[92] Lin, Q.; Liu, L.; Zheng, F.; Mao, P. P.; Liu, J.; Zhang, Y. M.; Yao, H.; Wei, T. B. Tetrahedron 2017, 73, 5307.

[93] Momeni, S.; Ahmadi, R.; Safavi, A.; Nabipour, I. Talanta 2017, $175,514$.

[94] Männel-Croisé, C.; Zelder, F. ACS Appl. Mater. Interfaces 2012, 4, 725

[95] Zong, C.; Zheng, L. R.; He, W.; Ren, X.; Jiang, C.; Lu, L. Anal. Chem. 2014, 86, 1687.

[96] Lin, Q.; Lu, T. T.; Zhu, X.; Sun, B.; Yang, Q. P.; Wei, T. B.; Zhang, Y. M. Chem. Commun. 2015, 51, 1635.

[97] Barare, B.; Babahan, I.; Hijji, Y. M.; Bonyi, E.; Tadesse, S.; Aslan, K. Sensors 2016, 16, 271.

[98] Incel, A.; Akın, O.; Căgır, A.; Yıldız, Ü. H.; Demir, M. M. Sens. Actuators, B 2017, 252, 886.

[99] Kim, M. J.; Manivannan, R.; Kim, I. J.; Son, Y. A. Sens. Actuators, B 2017, 253, 942.

[100] Maurya, N.; Singh, A. K. Sens. Actuators, B 2017, 245, 74.

(Li, L.; Fan, Y.) 